\title{
Ground-based lidar measurements from Ny-Ålesund during ASTAR 2007
}

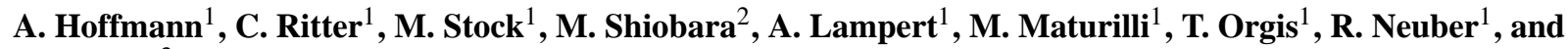 \\ A. Herber ${ }^{3}$ \\ ${ }^{1}$ Alfred Wegener Institute for Polar and Marine Research in the Helmholtz Association, Telegrafenberg A 43, \\ 14473 Potsdam, Germany \\ ${ }^{2}$ National Institute of Polar Research, Kaga 1-9-10, Itabashi-ku, Tokyo, 190-8518 Japan \\ ${ }^{3}$ Alfred Wegener Institute for Polar and Marine Research in the Helmholtz Association, Bürgermeister-Smidt-Straße 20, \\ 27568 Bremerhaven, Germany
}

Received: 7 July 2009 - Published in Atmos. Chem. Phys. Discuss.: 20 July 2009

Revised: 16 October 2009 - Accepted: 20 November 2009 - Published: 30 November 2009

\begin{abstract}
During the Arctic Study of Tropospheric Aerosol, Clouds and Radiation (ASTAR) in March and April 2007, measurements obtained at the AWIPEV Arctic Research Base in Ny-Ålesund, Spitsbergen at $78.9^{\circ} \mathrm{N}, 11.9^{\circ} \mathrm{E}$ (operated by the Alfred Wegener Institute for Polar and Marine Research - AWI and the Institut polaire français Paul-Emile Victor - IPEV), supported the airborne campaign. This included lidar data from the Koldewey Aerosol Raman Lidar (KARL) and the Micro Pulse Lidar (MPL), located in the atmospheric observatory as well as photometer data and the daily launched radiosonde. The MPL features nearly continuous measurements; the KARL was switched on whenever weather conditions allowed observations ( $145 \mathrm{~h}$ in 61 days). From 1 March to 30 April, 71 meteorological balloon soundings were performed and compared with the concurrent MPL measurements; photometer measurements are available from 18 March. For the KARL data, a statistical overview of particle detection based on their optical properties backscatter ratio and volume depolarization can be given. The altitudes of the occurrence of the named features (subvisible and visible ice and water as well as mixed-phase clouds, aerosol layers) as well as their dependence on different air mass origins are analyzed. Although the spring 2007 was characterized by rather clean conditions, diverse case studies of cloud and aerosol occurrence during March and April 2007 are presented in more detail, including temporal development and
\end{abstract}

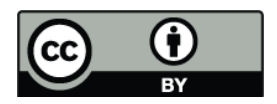

Correspondence to: A. Hoffmann (anne.hoffmann@awi.de) main optical properties as depolarization, backscatter and extinction coefficients. Links between air mass origins and optical properties can be presumed but need further evidence.

\section{Introduction}

The Arctic is considered to be a sensitive indicator of climate change due to a large number of special interactions and feedback mechanisms (Curry et al., 1996). Especially aerosols and clouds have a significant influence on the solar and terrestrial radiation budget (Shupe and Intrieri, 2004; Quinn et al., 2007). Formation, evolution and dissipation of clouds as well as sources and sinks of aerosol particles are not yet entirely understood. Therefore, data collection by ground-based and airborne experiments in this remote region is important (Solomon and Qin, 2007).

The ASTAR 2007 campaign was a follow-up of two aircraft campaigns in the Arctic in 2000 (Yamanouchi et al., 2005) and 2004 (Engvall et al., 2008), mainly focused on the measurement of aerosol and cloud properties in the polar troposphere. During ASTAR 2007, two research aircraft operating from the airport of Longyearbyen/Svalbard at $78^{\circ} \mathrm{N}$ were supported by ground based measurements from the AWIPEV Arctic Research Base in Ny-Ålesund amongst others. The campaign was conducted from 26 March until 18 April to capture the end of the Arctic Haze season where pollution events are expected to occur in the Arctic (Herber et al., 2002).

Published by Copernicus Publications on behalf of the European Geosciences Union. 
Arctic Haze (Quinn et al., 2007) in early spring and forest fire aerosols during summer (Stohl et al., 2007) are considered to be the main sources of optically active aerosols entering the Arctic. Although the non-seasalt (nss) sulphate transport into the Arctic in spring time decreased significantly after the early nineties (Quinn et al., 2007), haze events remain one of the most important air pollution events in this region for at least two reasons: first, during snowmelt the Arctic is especially climatologically sensitive due to the surface albedo effect (Stone et al., 2002) and second, the strongly developing East Asian countries (and potentially Russia) will possibly contribute to relevant emissions in the future (Koch and Hansen, 2005) at least in higher tropospheric layers (Stohl, 2006). While our knowledge about the pollution pathways into the Arctic improved significantly in recent years (Law and Stohl, 2007) a realistic aerosol forecast in this remote region is still not possible as aerosol removal processes, e.g. wet and dry deposition are insufficiently known. Wet deposition depends critically on the amount of water vapor and atmospheric trace gases in the atmosphere whereas dry deposition depends on turbulent transfer and mixing which leads to lifetimes as long as 30 days for particles around $0.2 \mu \mathrm{m}$ size in the dry and stable wintertime Arctic troposphere (Korhonen et al., 2008; Shaw, 1995).

Herber et al. (2002) presented a nine year time series of aerosol optical depth (AOD) for Ny-Ålesund derived by sun and star photometer which showed a constant level of aerosol contamination in time, despite of a general reduction of sulfur measured at the nearby Zeppelin station (Quinn et al., 2007). However, a continuous time series of lidar observations for an analysis of the vertical distribution, size and phase of occurring aerosol is still missing for Spitsbergen as lidar observations can only be performed at clear sky conditions with thin clouds or aerosols that do not blind the photomultipliers. Additionally, continuous measurements require manpower that is only available during campaigns like ASTAR.

While the ASTAR 2000 campaign was focused on tropospheric aerosol and radiation, for ASTAR 2004 and 2007 the research field was widened to cloud analysis. So far, Arctic clouds have mainly been investigated in different campaigns in the North American part of the Arctic e.g. during the Mixed-Phase Arctic Cloud Experiment (M-PACE 2004, Verlinde et al., 2007), the First International Satellite Cloud Climatology Project Regional Experiment Arctic Cloud Experiment (FIRE ACE 1998, Curry et al., 2000) or the Surface Heat Budget of the Arctic Ocean Project (SHEBA 19971998, Intrieri et al., 2002). As the Spitsbergen area is influenced by the warm Gulf Stream and characterized by different air mass pathways and a different orography than the same latitudes in the North American part of the Arctic, occurrence, properties and impact of clouds as well as aerosols can be very different.

The total Arctic cloud cover varies seasonally with less cloud cover during winter (40-80\%) and more during sum- mer (80-90\%) (Curry et al., 1996; Intrieri et al., 2002; Schweiger et al., 1999; Shiobara et al., 2003) as well as regionally e.g. due to local meteorological conditions. Also an annual variation with North Atlantic oscillation (NAO) phase is possible (Intrieri et al., 2002).

Clouds show a variety of different forms and therefore scattering properties. Within the Arctic troposphere one can distinguish ice clouds, water clouds and mixed-phase clouds whereas the latter ones are the most difficult to describe (Morrison et al., 2008). Characteristic features of mixedphase clouds include the occurrence of a liquid layer on top of the cloud (Shupe et al., 2008; Lampert et al., 2009) and the frequent existence of clouds within the boundary layer close to temperature inversions (Kahl, 1990).

The challenges for precise cloud parameterization in the Arctic were recently pointed out by Wyser et al. (2008) in a comparison of eight current regional climate models. The models were validated against cloud properties obtained during the SHEBA campaign (Curry et al., 1996). Currently, cloud parameterizations distinguish ice and liquid phase of mixed-phase clouds mainly as a function of temperature alone and are in need of improvement of Arctic cloud parametrization (Vavrus and Waliser, 2008). On the other hand measurements have shown that the liquid water content at low temperatures is sometimes higher than expected and that apart from temperature other parameters such as cooling rates must be considered as well (Pinto et al., 2001). The influence of Arctic aerosol on the climate and radiation budget has been discussed in Treffeisen et al. (2005) and Rinke et al. (2004). Even small and uniformly distributed aerosol can significantly alter the atmospheric state. Hence, especially in this relatively pristine environment the precise description of aerosol properties and clouds in climate models is of importance.

The AWIPEV research station in Ny-Ålesund, Spitsbergen, a uniquely well equipped Arctic laboratory, provides long term remote sensing technologies. In this study we combined lidar, sun photometer and balloon sounding measurements to characterize the Arctic atmosphere in March and April 2007. As observational data in the Arctic are sparse and model parameterizations are usually tested against older campaign data, we used the special opportunity to run the KARL lidar (Ritter et al., 2004) between 1 March and 30 April whenever possible. Thick low level clouds would have blinded the detectors so the lidar was not switched on when the sky was overcast. With KARL $145 \mathrm{~h}$ of evaluable lidar data were gathered, while the MPL yielded 47 days of lidar data.

This allows us to give a statistical overview of the Arctic spring time in the year 2007. Due to the high interannual variability of the Arctic climate (Eckhardt et al., 2003) this analysis is still only a snapshot, observations of other years might differ substantially. 


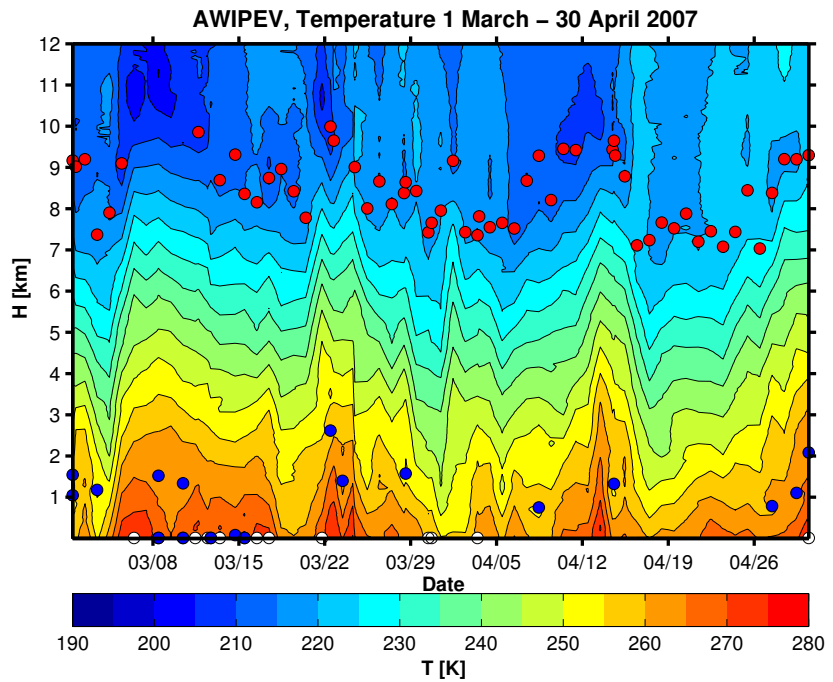

Fig. 1. Temperature profiles obtained with 71 radio soundings from 1 March to 30 April 2007, contour interval: $5 \mathrm{~K}$, red dots: tropopause, blue dots: temperature inversions above $2 \mathrm{~K}$, white dots: surface-based temperature inversions above $0.5 \mathrm{~K}$.

\section{Meteorological conditions in March and April 2007}

In this chapter, an overview of the meteorological data obtained with radiosonde launches and photometer measurements as well as calculations of backward trajectories are presented.

\subsection{Balloon soundings}

Within the analyzed two months period, 71 weather balloons with Vaisala RS92 radiosondes (Vömel et al., 2007) have been launched at the AWIPEV base (38 in March and 33 in April). The soundings provide profiles of air temperature, relative humidity, wind speed and wind direction usually up to the mid stratosphere. The temperature $\mathrm{T}$ is measured using a capacitive wire and can be obtained with a resolution of $0.1 \mathrm{~K}$ and a total uncertainty of $0.2 \mathrm{~K}$ in the troposphere. The relative humidity RH can be measured between 0 and $100 \%$ with a resolution of $1 \%$ and an accuracy of $5 \%$ at $-50^{\circ} \mathrm{C}-$ the colder the temperature the larger becomes the insecurity (Miloshevich et al., 2006; Währn et al., 2004). More details on radiosounding at the AWIPEV Arctic Research Base can be found in Treffeisen et al. (2007).

\subsubsection{Temperatures}

An overview of the temporal temperature evolution is given in Fig. 1. The temperature on the ground varied between 255 and $275 \mathrm{~K}$. The tropopause was calculated using the World Meteorological Organization (WMO) definition (WMO, 2008) and is marked with red dots in Fig. 1. Its height varied between 7 and $10 \mathrm{~km}$ with temperatures of 200

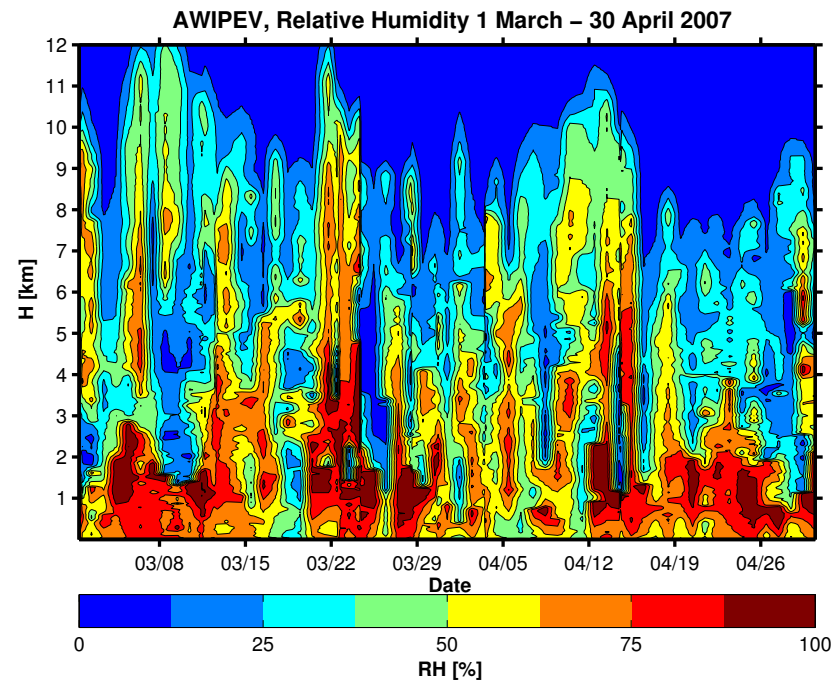

Fig. 2. Relative humidity profiles obtained with 71 radio soundings from 1 March to 30 April 2007, contour interval: $12.5 \%$.

to $225 \mathrm{~K}$. In mid April stratospheric temperatures increased due to the the break-up of the polar vortex.

A frequent Arctic phenomenon are low level temperature inversions, which are forced by strong radiative cooling of the surface and inhibit the mixing of the air in the lowermost troposphere with that of the overlying free troposphere. Thus, they play an important role in the dynamics of the Arctic planetary boundary layer (Kahl, 1990). We analyzed the occurrence of inversions below $6 \mathrm{~km}$ altitude using the 71 obtained temperature profiles in the original resolution of $5 \mathrm{~s}$ read-out, which equates to a vertical resolution of about $25 \mathrm{~m}$. The algorithm added up the temperature difference between two adjacent height steps as long as it was positive. In Fig. 1 temperature inversions of more than $2 \mathrm{~K}$ are marked with blue dots. In March they were observed frequently, declining in April. The white dots mark the surfacebased temperature inversions above $0.5 \mathrm{~K}$, whose inversion base was below $25 \mathrm{~m}$ (Kahl, 1990), lower temperature differences were neglected. 13 out of the 15 surface-based inversions were observed in March, including the four events with surface-based inversions stronger than $2 \mathrm{~K}$. By beginning of March, the radiation deficit is reduced by a rapid increase in solar flux. Therefore the surface temperature rises in spring and the thermal stability near the surface decreases. Simultaneously, the cloudiness also increases, weakening the inversion through the increased longwave radiative flux to the surface.

\subsubsection{Relative humidity}

Another quantity measured by the Vaisala sondes is the relative humidity. It can be seen that the relative humidity decreases with height as well (Fig. 2). Below $1 \mathrm{~km}$ the relative 
humidity was above $30 \%$, decreasing towards higher altitudes with no higher values than $70 \%$ above $7 \mathrm{~km}$. Also, it showed a very high day-to-day variability.

For comparison with KARL lidar data (see Sect. 4) we calculated the relative humidity over ice using the Goff Gratch Eq. (Buck, 1981). It showed higher values of up to $120 \%$, saturation also occurred in the upper troposphere.

\subsection{Aerosol optical depth and backward trajectories}

The optical depth was measured using a sun photometer type SP1A produced by Dr. Schulz and Partner GmbH. The SP1A has a field of view of $1^{\circ}$ and covers a spectral range from $350 \mathrm{~nm}$ to $1050 \mathrm{~nm}$ in 17 channels. A detailed description of the instrument and the performed measurements in $\mathrm{Ny}$ Ålesund can be found in Herber et al. (2002). Due to the polar night conditions, first measurements could not be performed before 18 March. The obtained aerosol optical depth (AOD) at $500 \mathrm{~nm}$ was determined to $0.05 \pm 0.02$ in March with an increasing tendency in April $(0.08 \pm 0.03)$. Compared to the mean values for the period from 1995 to 2008 of 0.1 this is comparably low. These low values already indicate that from the point of view of optical remote sensing instruments, the spring 2007 was very clean with a paucity of obvious Arctic Haze events.

To determine the dominating weather patterns during March and April 2007, three-dimensional backward trajectories were calculated using the Pole-Equator-Pole-Tracer (PEP-Tracer) model (Orgis et al., 2009) with wind fields from the European Center for Medium Range Weather Forecast (ECMWF). For each day 5-day backward trajectories at three pressure levels (500, 700 and $850 \mathrm{hPa}$ ) and four starting times per day (00:00, 06:00, 12:00 and 18:00 UTC - coordinated universal time) were calculated using ensemble calculations of ca. 1000 trajectories. The statistical spread of the trajectory ensembles was determined to be $\pm 400 \mathrm{~km}$. A use of longer trajectories is not reasonable as the cumulative errors in the particle location become very large. Cluster analysis with a total number of eight clusters was performed to classify the trajectories into transport patterns, analyzing the spacial variance between different trajectories. The number of eight clusters was found to be optimal for the $\mathrm{Ny}$-Ålesund region by Eneroth et al. (2003), who did a similar analysis for the 10-year period from 1992-2001. For further analysis the trajectories arriving at $700 \mathrm{hPa}$ were considered as they characterize the mid-troposphere and the main patterns were similar for the two other pressure levels. In Fig. 3, the trajectories for the $700 \mathrm{hPa}$ level merged to eight different clusters are shown. The cluster analysis in Eneroth et al., 2003 identifies cluster 1, 2 and 4 (transport from Eurasia) to be more frequent in March and April than during the rest of the year $(47.1 \%$ compared to $39.6 \%$ ) for the 10 -year-period 1992-2001. In our analysis for 2007, the value is with $30.0 \%$ even lower than the annual mean (see Table 1).

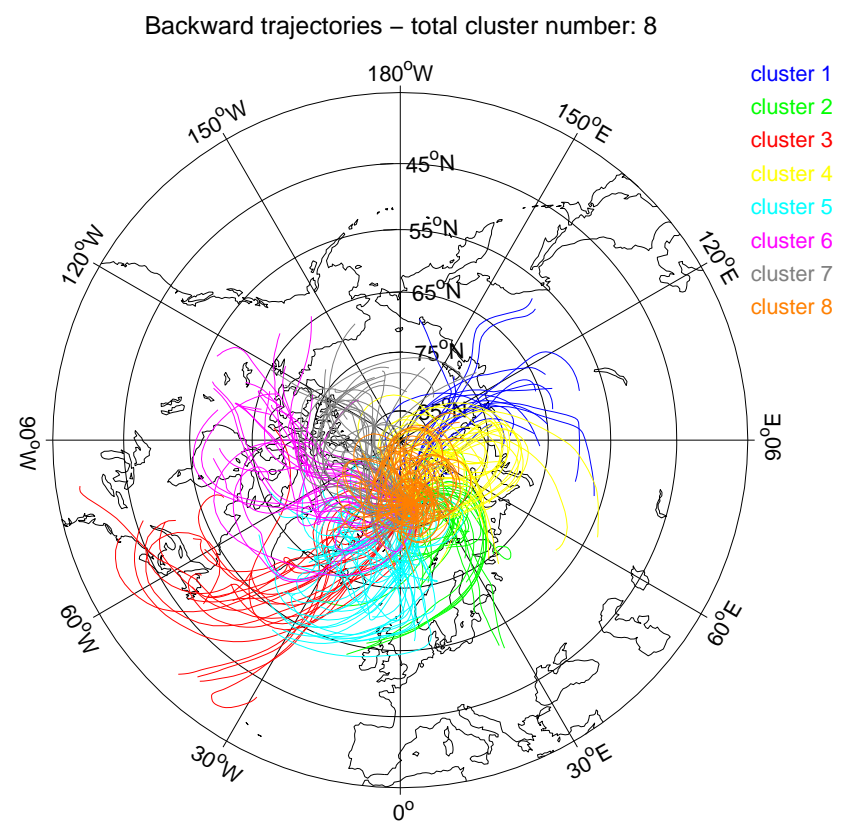

Fig. 3. Cluster analysis for the 5 -day backward trajectories $(700 \mathrm{hPa}$ level) performed with the PEP-Tracer model.

Comparing the ASTAR time period (26 March to 18 April) with the whole two months, strong differences are apparent. During ASTAR, the clusters 6 and 7, representing winds from the Canadian Arctic and the Beaufort Sea are prevalent (40.2\% compared to $31.1 \%$ in March and April), while cluster 2, 5 and 8, showing transport from the European continent and the central Arctic are underrepresented (20.8\% compared to $49.6 \%$ in March and April). This documents the very clean atmospheric conditions during the ASTAR campaign possibly due to less pollution sources in northern Canada (Law and Stohl, 2007).

\section{Cloud statistics from lidar measurements}

There are measurements of two different lidar systems available, the Koldewey Aerosol Raman Lidar (KARL) and the Micro Pulse Lidar (MPL). For the cloud statistics, the complete available dataset of the two lidar systems was analyzed. Both systems are described in Sect. 3.1. The MPL data $(1368 \mathrm{~h})$ were used for a comparison with the temperature and relative humidity profiles obtained with the proximate balloon soundings (Sect. 3.3.1) and in a second analysis to retrieve a general overview in terms of cloud altitudes (Sect. 3.3.2). The KARL data ( $145 \mathrm{~h}$ ) were examined to separate between aerosol and cloud events and to analyze trends in depolarization and backscatter values depending on the altitude and corresponding backward trajectory. 
Table 1. Observed frequency of occurrence of the eight different trajectory clusters (see Fig. 3), the * denotes cluster analysis from Eneroth et al. (2003).

\begin{tabular}{lrrrrrrrr}
\hline & 1 & 2 & 3 & 4 & 5 & 6 & 7 & 8 \\
\hline March/April 2007 & 7.0 & 10.7 & 8.6 & 12.3 & 20.5 & 10.7 & 11.9 & 18.4 \\
ASTAR 2007 & 8.3 & 0 & 11.5 & 17.7 & 10.4 & 19.8 & 21.9 & 10.4 \\
Annual Mean 92-01* & 15.2 & 13.3 & 9.2 & 11.1 & 8.3 & 16.7 & 9.4 & 16.9 \\
March/April 92-01* & 17.6 & 17.5 & 10.0 & 12.0 & 7.0 & 13.0 & 7.9 & 15.2 \\
\hline
\end{tabular}

\subsection{Lidar systems}

The Micro Pulse Lidar (MPL) is a compact, continuously operating lidar system (Welton and Campbell, 2002; Spinhirne, 1993), that is running on a twenty-four hour operation basis at AWIPEV Arctic Research Base and maintained by the base personnel since June 2003. It uses a Nd:YLF laser $(\lambda=523.5 \mathrm{~nm})$ and a Schmidt-Cassegrain telescope with $20 \mathrm{~cm}$ diameter for laser transmission and receiving. The main parameters of the system are listed in Shiobara et al. (2003). The measured backscatter profiles cover a range of $60 \mathrm{~km}$ with a vertical resolution of $30 \mathrm{~m}$ and a temporal average of $1 \mathrm{~min}$. The system was working continuously over the whole 2 months period with some data losses (altogether 14 days) due to snow on the window, which has to be removed manually. For further analysis the data from 1 March until 30 April was averaged to means of $10 \mathrm{~min}$, background corrected and cut above $21 \mathrm{~km}$.

The Koldewey Aerosol Raman Lidar (KARL) is a Nd:YAG based Raman lidar. It measures the elastically backscattered light in three wavelengths $(355 \mathrm{~nm}, 532 \mathrm{~nm}$ and $1064 \mathrm{~nm}$ ) as well as the $\mathrm{N}_{2}$ shifted lines from the $2 \mathrm{nd}$ and 3rd harmonic. Additionally, a water vapor channel at $407 \mathrm{~nm}$ as well as depolarization at $532 \mathrm{~nm}$ are recorded. From the two $\mathrm{N}_{2}$ shifted lines $387 \mathrm{~nm}$ and $607 \mathrm{~nm}$, the extinction coefficient can be determined, making KARL a " $3+2$ " wavelengths Raman lidar. In the ASTAR 2007 configuration the field of view of the $30 \mathrm{~cm}$ mirror was $0.83 \mathrm{mrad}$. In November 2006 a new laser (Spectra Pro 290-50), which works at $50 \mathrm{~Hz}$ and yields more than $10 \mathrm{~W}$ power at $355 \mathrm{~nm}$ and $532 \mathrm{~nm}$ and $20 \mathrm{~W}$ at $1064 \mathrm{~nm}$, was installed in the lidar, increasing the energy output by a factor of 5 which significantly improved the data quality (Ritter et al., 2008). After beam widening the laser beam had an effective divergence of $0.5 \mathrm{mrad}$. With $10 \mathrm{~min}$ integration time and $60 \mathrm{~m}$ height resolution the elastic wavelengths are easily evaluable up to $25 \mathrm{~km}$ altitude in daylight conditions.

KARL can only be operated when the backscattered fraction of the light is not too strong in order not to damage the photomultipliers. This inhibits the evaluation of optically thick clouds with high backscatter, especially in the lower altitudes as the dynamic range of lidar return signals is inversely proportional to the distance $\mathrm{z}^{2}$. In total, almost $150 \mathrm{~h}$ of lidar data were collected with KARL. About four hours of data could not be evaluated due to low laser power, optical adjustments and multiple scattering at clouds with an optical depth above 0.55. These data sets were excluded from this study. Hence, we restrict ourselves to clear sky conditions and clouds with low optical thickness and neglect multiple scattering in this study. About $145 \mathrm{~h}$ of trustful data remained.

Therefore, the available dataset is much smaller than the MPL's data set and a statistical evaluation of cloud occurrence in the strict sense is impossible. However, we analyzed the frequency of occurrence of different atmospheric structures and classified them according to backscatter ratio and volume depolarization.

\subsection{Lidar data analysis}

For the analysis of the retrieved signal profiles, the Klett algorithm (Klett, 1981) was used. Assuming a constant lidar ratio $\mathrm{LR}=30$ defined as the quotient between the aerosol backscatter coefficient $\beta^{\text {aer }}$ (BC) and the aerosol extinction coefficient $\alpha^{\text {aer }}$, profiles of $\beta^{\text {aer }}$ were calculated. The backscatter ratio (BSR) for a given wavelength $\lambda$ at range $z$ is defined as

$\operatorname{BSR}(\lambda, z)=\frac{\beta^{\text {ray }}(\lambda, z)+\beta^{\text {aer }}(\lambda, z)}{\beta^{\text {ray }}(\lambda, z)}$

where $\beta^{\text {ray }}$ is the molecular Rayleigh backscatter coefficient. Note that aerosol backscattering refers to larger particles which also includes cloud droplets or crystals. If not further specified, BSR always corresponds to the particle/aerosol backscatter ratio at $532 \mathrm{~nm}$ ( $523 \mathrm{~nm}$ for the MPL).

Furthermore, the volume depolarization (VD) can be estimated measuring the backscattered signal in parallel and perpendicular polarization to the polarization of the transmitted beam.

$\mathrm{VD}(\lambda, z)=\frac{P^{\operatorname{perp}}(\lambda, z)}{P^{\operatorname{par}}(\lambda, z)}$

The quotient is normalized in the aerosol and cloud free stratosphere in $14 \mathrm{~km}$ altitude assuming a background value of $1.4 \%$ which occurs due to Rayleigh scattering. The volume depolarization is an indicator for particle shapes and 
hence state of aggregation (Pal and Carswell, 1973) and can be measured with KARL for the elastic $532 \mathrm{~nm}$ channel.

Measurements of the backscatter ratio at different wavelengths allow the calculation of the color ratio CR (Beyerle et al. , 2001), which is a measure of the particle size.

$\operatorname{CR}\left(\lambda_{1}, \lambda_{2}, z\right)=\frac{\operatorname{BSR}\left(\lambda_{1}, z\right)-1}{\operatorname{BSR}\left(\lambda_{2}, z\right)-1} \quad$ with $\quad \lambda_{1}>\lambda_{2}$

A color ratio close to unity indicates small particles, while large CR values indicate large particles compared to the wavelength. In this paper CR in the visible $(532 \mathrm{~nm})$ refers to $\lambda_{1}=1064 \mathrm{~nm}$ and $\lambda_{2}=532 \mathrm{~nm}, \mathrm{CR}$ in the UV to $\lambda_{1}=532 \mathrm{~nm}$ and $\lambda_{2}=355 \mathrm{~nm}$, respectively.

The spectral dependence of the AOD $\tau$ with the wavelength $\lambda$ is expressed by the Angström exponent $\alpha$ (Ångström, 1964)

$\tau(\lambda) \propto \lambda^{-\alpha}$.

The Ångström exponent (Hamonou et al., 1999) provides additional information on the particle size, the larger the exponent, the smaller the particles.

Multiple scattering causes the lidar return signal from clouds to increase with increasing receiver field of view (FOV) (Eloranta, 1998) and optical thickness of the cloud (Hu et al., 2006; Cho et al., 2008). For the MPL, multiple scattering can be neglected as it has no significant influence on the qualitative cloud altitude detection. KARL statistics refer to rather clear conditions, a few data sets with clouds showing multiple scattering (approx. at BSR $>50$ in $5 \mathrm{~km}$ altitude) have been removed.

\subsection{MPL statistics}

For ten altitude intervals of $1 \mathrm{~km}$ width, the retrieved BSR profiles were analyzed to find cloud structures within the interval. Different thresholds for the difference between two adjacent BSR values were used, which were determined conducting sensitivity studies. For each altitude interval beginning at the surface (the first interval was restricted to $100 \mathrm{~m}-$ $1 \mathrm{~km}$ due to incomplete overlap, see Chazette (2003)), BSR differences above 0.1 in conjunction with increasing BSR values for at least 3 height steps or a single BSR peak difference of minimal 0.2 were needed to detect a cloud. Furthermore, in case of low cloud detection (below $5 \mathrm{~km}$ ) the detection of clouds above $5 \mathrm{~km}$ was only accepted to be true if the signal to noise ratio (SNR) between 5.5 and $10 \mathrm{~km}$ was above a threshold value of 15 . Therefore the data about the occurrence of clouds in the upper intervals is less reliable. Profiles with snow on the window can also be detected, looking for a strong backscatter peak at an altitude below $300 \mathrm{~m}$.

\subsubsection{Correlation of radiosonde and MPL data}

For the following analysis the three subsequent MPL profiles after each balloon launch were evaluated since the weather
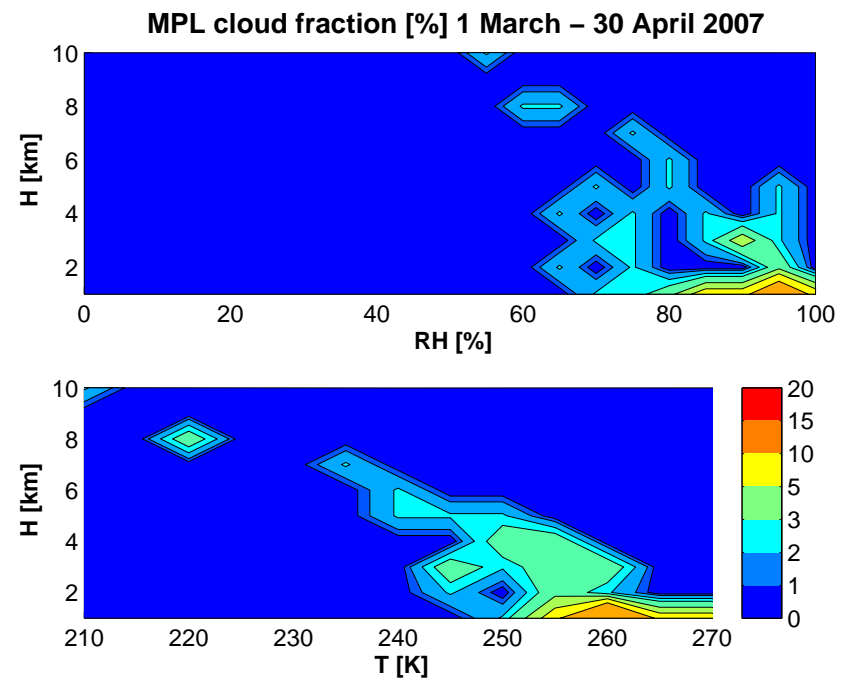

Fig. 4. MPL cloud fraction in ten altitude intervals of $1 \mathrm{~km}$ width depending on relative humidity and temperature, derived from the comparison of 57 radiosondes with respective MPL data.

balloons take about $30 \mathrm{~min}$ to reach the tropopause. The profiles were averaged and the backscatter ratio was calculated with the Klett algorithm (Klett, 1981).

The following analysis was done for 57 balloon soundings as in the other cases the MPL window was covered with snow. For the analysis shown in Fig. 4, the 57 temperature profiles were averaged over the 10 altitude intervals, for each interval maximum relative humidity was listed. On the $\mathrm{x}$ axis, the relative humidity and temperature are plotted respectively, on the y-axis the altitude interval, color coded is the frequency of occurrence of clouds in the MPL data in the particular interval. One has to be aware of the fact that due to the averaging process, peak values in temperature are suppressed. In addition the movement of the balloons in zonal and meridional direction cannot be ignored. The comparison with the humidity data shows that below $7 \mathrm{~km}$, no clouds were observed at a mean relative humidity below $60 \%$. For the humidity over ice, clouds were only detected in altitude intervals with at least 50\% relative humidity over ice (not shown). For the actual formation of clouds, the peak values are expected to be higher as our analysis uses averaged data and is only suitable for estimating minimal values. Although clouds mainly occur above $230 \mathrm{~K}$, clouds were also found in higher altitudes at temperatures of $210 \mathrm{~K}$. For the temperature analysis, the averaging error is small compared to the general lack of high cloud detection due to thicker low clouds (Shiobara et al., 2006). Further analyses with the KARL depolarization channel will be done in Sect. 3.4 to estimate the respective cloud phase. 


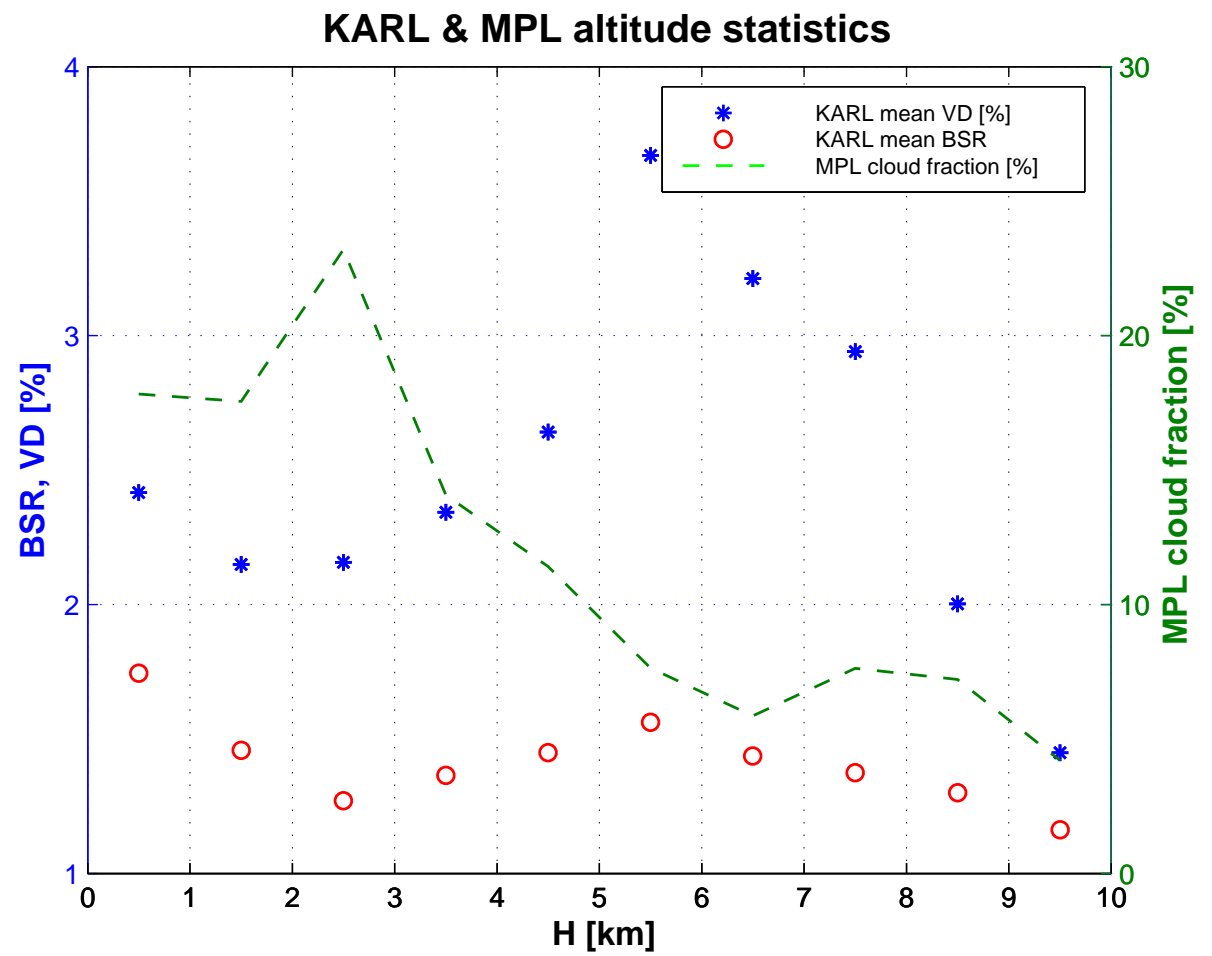

Fig. 5. 1-km means of BSR and VD for KARL data and frequency of cloud occurrence for MPL data for ten altitude intervals, the MPL clear sky fraction was $33 \%$.

Table 2. KARL backscatter ratio (BSR at $532 \mathrm{~nm}$ ) according to altitude intervals. Given is the median value as well as frequency of certain BSR values within the different altitude intervals.

\begin{tabular}{lrrrrrrr}
\hline $\mathrm{H}[\mathrm{km}]$ & median BSR & $10-3$ & $3-2$ & $2-1.5$ & $1.5-1.2$ & $1.2-1.1$ & $1.1-1.05$ \\
\hline $9-10$ & 1.093 & 0 & 0 & 0 & 1.3 & 31.2 & 67.5 \\
$8-9$ & 1.100 & 1.0 & 1.7 & 1.3 & 4.3 & 43.8 & 44.0 \\
$7-8$ & 1.103 & 2.2 & 2.2 & 3.0 & 5.7 & 42.8 & 44.0 \\
$6-7$ & 1.105 & 3.0 & 2.2 & 3.2 & 8.9 & 43.4 & 39.2 \\
$5-6$ & 1.112 & 2.3 & 2.8 & 5.8 & 11.4 & 42.8 & 34.9 \\
$4-5$ & 1.124 & 4.9 & 5.2 & 6.1 & 15.8 & 38.2 & 29.8 \\
$3-4$ & 1.126 & 2.1 & 0.3 & 3.0 & 16.8 & 51.8 & 25.9 \\
$2-3$ & 1.142 & 1.5 & 1.4 & 4.4 & 22.4 & 45.8 & 24.6 \\
$1-2$ & 1.178 & 1.3 & 1.1 & 2.1 & 33.2 & 37.2 & 24.9 \\
\hline
\end{tabular}

\subsubsection{Cloud altitudes and cloud fraction}

As described in Lampert et al. (2009) the ASTAR 2007 cloud cover analysis over Ny-Ålesund showed an increasing fraction of low level and boundary layer clouds in the second half of April. Here, this analysis is redone using the algorithm above for the whole set of 10-min profiles. The choice of 1-km intervals within the troposphere can be justified with the vertical resolution of current climate models e.g. in Pfeiffer, 2006, which averages 9 to 10 levels between 850 and $300 \mathrm{hPa}$. The frequency of cloud occurrence in the different altitude intervals is marked with the dashed green curve in Fig. 5. Profiles with snow on the window (14 days total) are not considered. Low clouds between 1 and $4 \mathrm{~km}$ dominate, while there is another peak for higher clouds between 7 and $8 \mathrm{~km}$. The mean cloud altitude is between 4 and $4.5 \mathrm{~km}$, which is in accordance with the mean cloud top height at $80^{\circ} \mathrm{N}$ retrieved in Berthier et al. (2008) using satellite measurements. The clear sky fraction, which is the fraction of time where the MPL did not detect any cloud in any altitude interval is estimated to be $33 \%$. To calculate the total occurrence of cloud cover one would have to guess the cloudiness for the time fraction when the window was snow covered. Assuming this cloudiness to be $100 \%$ in the worst case and 


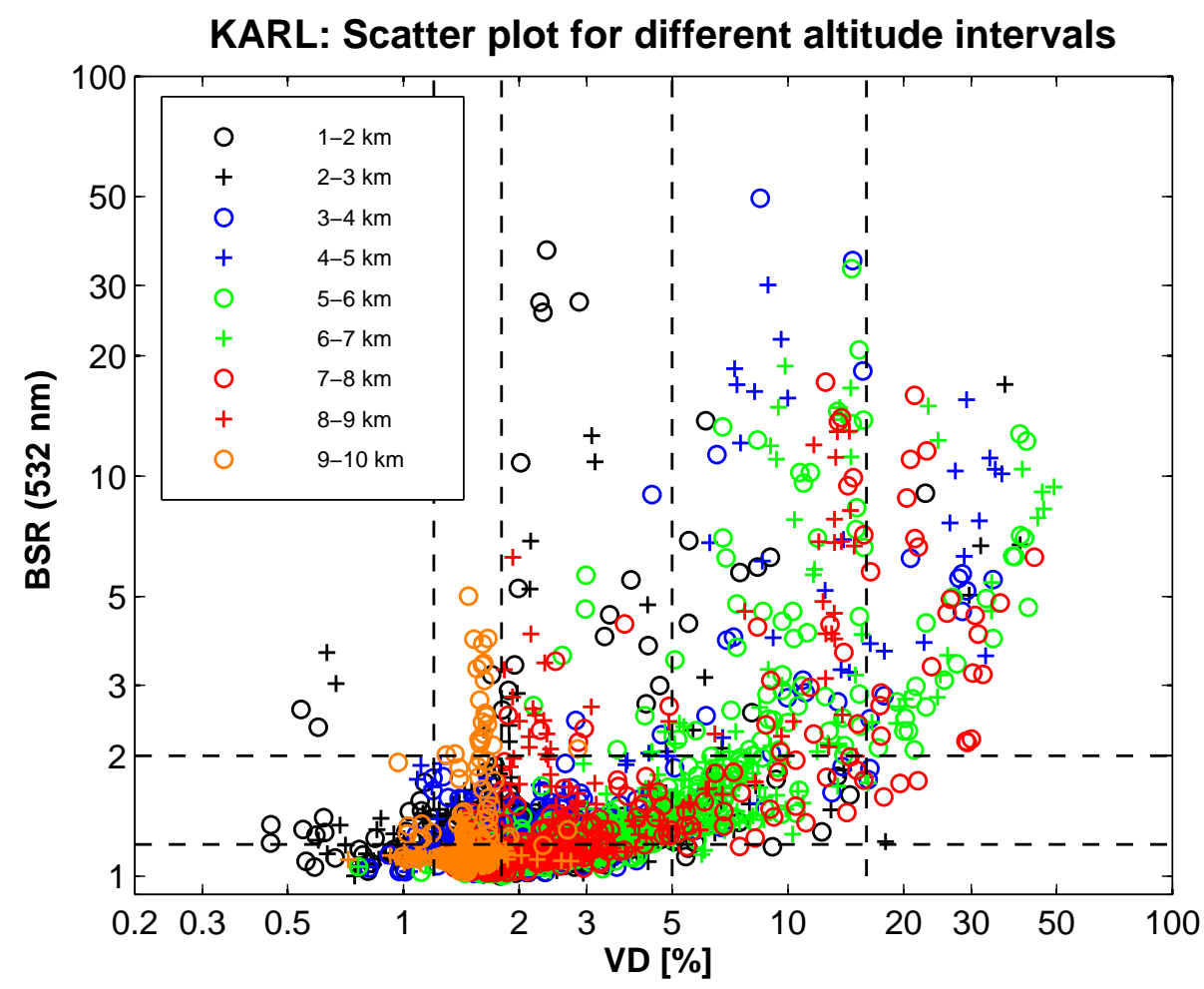

Fig. 6. Scatter plot of volume depolarization VD vs. backscatter ratio BSR $(532 \mathrm{~nm})$ for nine altitude intervals, the lowest interval was neglected due to high uncertainties. Dashed lines refer to BSR and VD thresholds defined in Sect. 3.4.2.

$67 \%$ as in the snow-free times in the best case, the total occurrence of clouds can be estimated to be between 67 and $78 \%$. Other measurements on site carried out by Shiobara et al. (2003) showed about 85\% cloud cover in March and April 2002. During the SHEBA campaign the cloud fraction in March/April 1998 was detected to be $83 \%$ while ISCCP satellite measurements for the Arctic regions in 1998 show lower values of 63\% (Intrieri et al., 2002; Curry et al., 1996).

\subsection{KARL statistics}

For the following analysis all 798 10-min profiles were considered. Within this section, all values were calculated as means in the same altitude intervals used for the MPL cloud analysis in Sect. 3.3.2, while the case studies in Sect. 4 are conducted with the $10 \mathrm{~min}$ and $60 \mathrm{~m}$ resolution. The mean backscatter ratio at $532 \mathrm{~nm}$ and depolarization values depending on the altitude interval can be seen in Fig. 5. Less or thinner clouds were observed between 3 and $5 \mathrm{~km}$, the strongest depolarization occurred between 6 and $10 \mathrm{~km}$. This feature of height-increasing depolarization has been found in different studies (Sassen and Benson, 2001) but generally for higher tropospheric temperatures. A quantitative comparison with the MPL data is not possible due to the different data sets and their respective limitations.

Table 2 summarizes the occurrence of observed backscatter ratios at $532 \mathrm{~nm}$ for selected height intervals. The median value and the percentile distribution of the backscatter ratio for height intervals in the troposphere are given. The mean value would have been affected by the few strongest cloud cases. At our Arctic site, generally the backscatter ratio decreases with altitude. The strongest signals $\mathrm{BSR}>2$, astonishingly, are observed most frequently in a layer of $4-5 \mathrm{~km}$ altitude. We rate this as a real feature, because cases with BSR $>10$ which might have led to a saturation of the photomultipliers in low, but not in higher altitudes, have not been considered in this table.

\subsubsection{Scatterplots}

For the analysis of the backscatter ratio BSR and the respective volume depolarization VD, Fig. 6 shows a scatter plot with different symbols for the different altitude intervals. High depolarization with low backscatter values indicating thin cirrus clouds is found between 4 and $8 \mathrm{~km}$, while the opposite indicating water clouds can be found in the lowest 3 intervals. The interval between 0 and $1 \mathrm{~km}$ was neglected as the data are not reliable due to an incomplete overlap function. Mean values over the altitude intervals are shown, some water clouds or water layers with little VD and BSR average out and peak values can exceed the shown ones.

In Fig. 7 the characteristics for the two altitude intervals from 2 to 3 and 3 to $4 \mathrm{~km}$ depending on the origin of the air masses are plotted. Each 10-min interval was assigned 
KARL: Scatter plot for different clusters

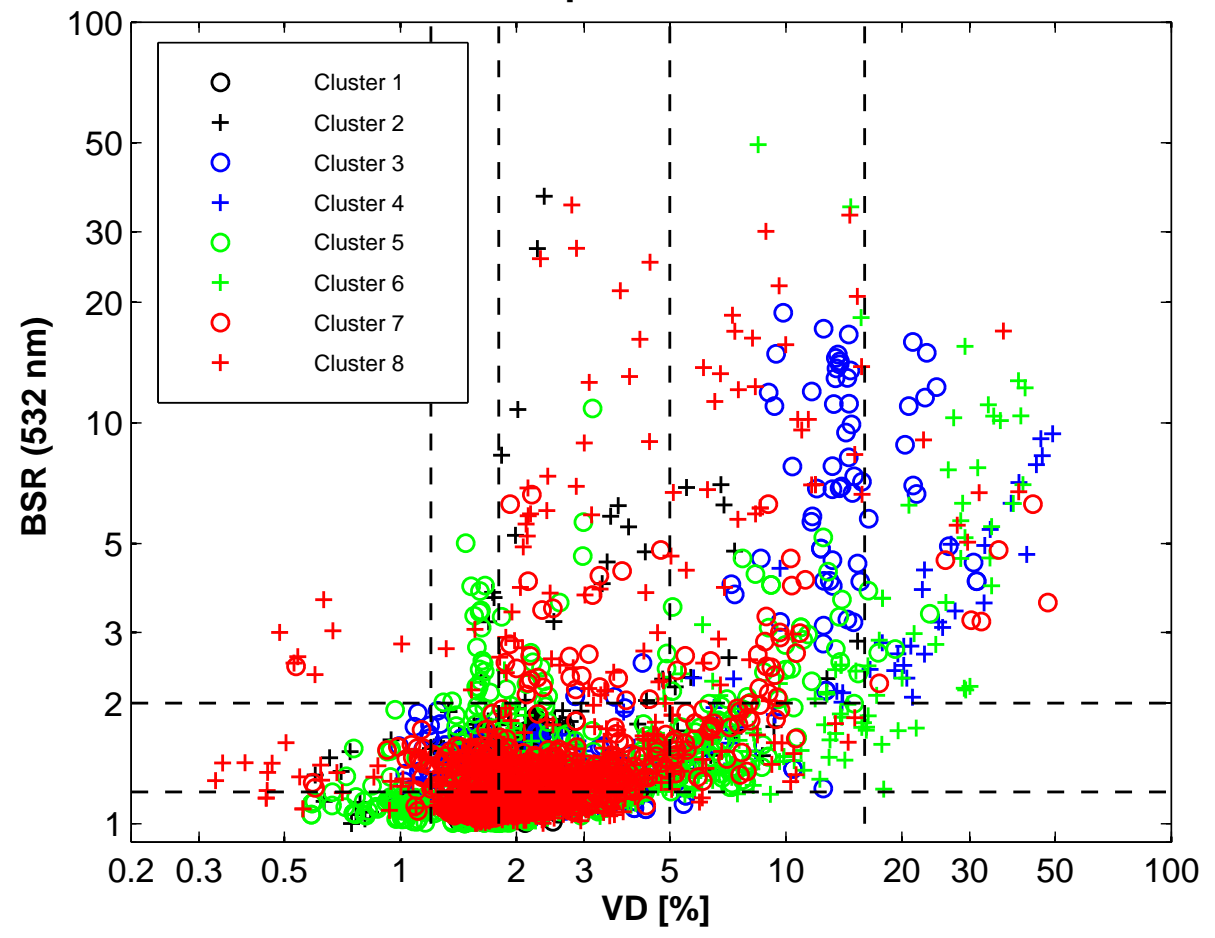

Fig. 7. Scatter plot of volume depolarization VD vs. backscatter ratio BSR $(532 \mathrm{~nm})$ for the eight trajectory clusters (see Fig. 3). Dashed lines refer to BSR and VD thresholds defined in Sect. 3.4.2.

Table 3. KARL data classification cases with respective VD and BSR thresholds and case studies.

\begin{tabular}{lllll}
\hline & & $\mathrm{BSR}$ & $\mathrm{VD}$ & case studies \\
\hline $\mathrm{C} 1:$ & clear sky & $\mathrm{BSR}<1.2$ & $\mathrm{VD}<1.8$ & no case studies \\
$\mathrm{C} 2:$ & water & $\mathrm{BSR}>1.2$ & $\mathrm{VD}<1.2$ & 15.03. \\
$\mathrm{C} 3:$ & high BSR, low VD & $\mathrm{BSR}>1.2$ & $1.2<\mathrm{VD}<1.8$ & $08.03 . / 07.04 . / 13.03$. \\
$\mathrm{C} 4:$ & low BSR, high VD & $\mathrm{BSR}<1.2$ & $\mathrm{VD}>1.8$ & 15.03. \\
$\mathrm{C} 5:$ & thin aerosol & $1.2<\mathrm{BSR}<2$ & $1.8<\mathrm{VD}<5$ & $15.03 . / 18.03 . /(07.04)$. \\
$\mathrm{C} 6:$ & thick aerosol & $\mathrm{BSR}>2$ & $1.8<\mathrm{VD}<5$ & not observed \\
$\mathrm{C} 7:$ & thin ice, low VD & $1.2<\mathrm{BSR}<2$ & $5<\mathrm{VD}<16$ & $13.03 . / 15.03$. \\
$\mathrm{C} 8:$ & thick ice, low VD & $\mathrm{BSR}>2$ & $5<\mathrm{VD}<16$ & $13.03 . / 15.03$. \\
$\mathrm{C} 9:$ & thin ice, high VD & $1.2<\mathrm{BSR}<2$ & $\mathrm{VD}>16$ & 15.03. \\
$\mathrm{C} 10:$ & thick ice, high $\mathrm{VD}$ & $\mathrm{BSR}>2$ & $\mathrm{VD}>16$ & 15.03. \\
\hline
\end{tabular}

to the temporally closest calculated backward trajectory in $700 \mathrm{hPa}$ (see Sect. 2.2), color coded is the corresponding cluster number. Volume depolarization below $1.8 \%$ with increased BSR of more than 2 was only found for cluster 5, 7 and 8 which corresponds to air masses from Western Europe/East Atlantic, the Beaufort Sea and the central Arctic. This might be due to cyclones originating over the Atlantic and bringing warm air masses which leads to less formation of highly depolarizing ice particles. High volume depolarization above $10 \%$ with BSR $>2$ occurred in air masses 3, 4, 6 and 7, originating over the Atlantic, Western Siberia and the Canadian Arctic. Medium VD between 1.8 and 10\% was de- tected in air masses from the Canadian and the Central Arctic as well as from Europe (cluster 2, 6-8). The air masses originating from Europe might contain a considerable amount of aerosols (Stohl, 2006), but reliable correlations need a trajectory analysis over several years with corresponding lidar measurements.

\subsubsection{Case classification}

Despite overlapping properties of clouds and aerosols, we attempt a classification of different features depending on the measured volume depolarization and backscatter coefficient 
Table 4. KARL frequency of occurrence of cases $\mathrm{C} 1$ to $\mathrm{C} 10$ according to the data classification in Tab. 3 for different altitude intervals. Percentages are within an accuracy of $1 \%$, peak values of VD and BSR average out.

\begin{tabular}{lrrrrrrrrrr}
\hline $\mathrm{H}[\mathrm{km}]$ & $\mathrm{C} 1$ & $\mathrm{C} 2$ & $\mathrm{C} 3$ & $\mathrm{C} 4$ & $\mathrm{C} 5$ & $\mathrm{C} 6$ & $\mathrm{C} 7$ & $\mathrm{C} 8$ & $\mathrm{C} 9$ & $\mathrm{C} 10$ \\
\hline $10-12$ & 98 & 0 & 1 & 1 & 0 & 0 & 0 & 0 & 0 & 0 \\
$9-10$ & 92 & 1 & 7 & 0 & 0 & 0 & 0 & 0 & 0 & 0 \\
$8-9$ & 79 & 0 & 2 & 8 & 5 & 2 & 1 & 3 & 0 & 0 \\
$7-8$ & 67 & 0 & 1 & 16 & 6 & 1 & 3 & 2 & 0 & 3 \\
$6-7$ & 49 & 0 & 1 & 30 & 7 & 0 & 7 & 3 & 0 & 2 \\
$5-6$ & 37 & 0 & 1 & 35 & 10 & 1 & 6 & 6 & 0 & 3 \\
$4-5$ & 37 & 1 & 2 & 42 & 14 & 0 & 1 & 2 & 0 & 2 \\
$3-4$ & 44 & 0 & 6 & 29 & 15 & 0 & 1 & 2 & 0 & 1 \\
$2-3$ & 35 & 1 & 9 & 30 & 20 & 1 & 1 & 1 & 0 & 1 \\
$1-2$ & 20 & 2 & 13 & 36 & 22 & 2 & 1 & 1 & 0 & 0 \\
\hline
\end{tabular}

Table 5. KARL frequency of occurrence of cases $\mathrm{C} 1$ to $\mathrm{C} 10$ according to to the data classification in Table 3 for two different air mass origin areas. Considered are the means of the altitude intervals from 2 to $3 \mathrm{~km}$ and 3 to $4 \mathrm{~km}$ as this corresponds to the $700 \mathrm{hPa}$ trajectories used for the cluster analysis. Percentages are within an accuracy of $1 \%$, peak values of VD and BSR average out.

\begin{tabular}{lrrrrrrrrrr}
\hline & $\mathrm{C} 1$ & $\mathrm{C} 2$ & $\mathrm{C} 3$ & $\mathrm{C} 4$ & $\mathrm{C} 5$ & $\mathrm{C} 6$ & $\mathrm{C} 7$ & $\mathrm{C} 8$ & $\mathrm{C} 9$ & $\mathrm{C} 10$ \\
\hline Eurasia (Cluster 2, 5, 8) & 51 & 2 & 7 & 3 & 28 & 6 & 2 & 0 & 1 & 0 \\
Canada (Cluster 6, 7) & 13 & 3 & 11 & 37 & 28 & 1 & 5 & 2 & 0 & 0 \\
\hline
\end{tabular}

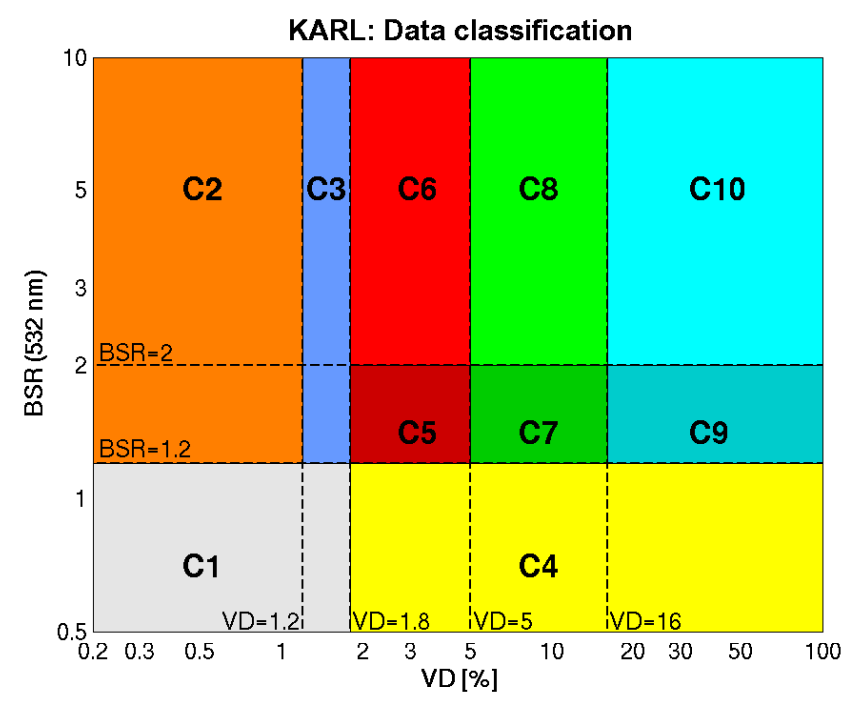

Fig. 8. KARL data classification according to VD and BSR threshold values.

values (see Table 3). We distinguish clear sky conditions (C1), water clouds (C2), high BSR and low VD (C3) as well as the opposite (C4), thin and thick aerosols (C5/6), thin and thick ice clouds with low VD (C7/8) and thin and thick ice clouds with high depolarization (C9/10). Additionally, Fig. 8 gives an overview of the threshold values for the ten cases; they are empirical values based on previous data analysis. In the cases of Arctic Haze in previous years (partly unpublished yet) we clearly see a depolarization between 2 and 5\% whereas cirrus observations suggest that a separation into medium and high depolarisation is justified. The backscatter ratio was divided into three categories: no particle backscatter above the background level $(\mathrm{BSR}<1.2)$, moderate backscatter $(1.2<\mathrm{BSR}<2)$ and strong backscatter $(\mathrm{BSR}>2)$.

This classification is an attempt to distinguish different measured phenomena with a lidar according to their scattering properties. As these phenomena do not show up separately at all times, additional measurements are needed to successfully analyze lidar data, e.g. lidar data in different elastic and inelastic wavelengths, temperature or relative humidity as well as AOD measurements or trajectory analysis. For instance, some ice particles do not show any depolarization due to their special shape and orientation (Hu et al., 2007) and aerosols also can have a wide variety of sizes, shapes and materials which leads to a range of different scattering properties (Dubovik et al., 2002). Especially in the outer regions of the diagram the information is quite valuable, e.g. cases $\mathrm{C} 1, \mathrm{C} 2, \mathrm{C} 4, \mathrm{C} 9, \mathrm{C} 10$. For the central regions, superposition of different phenomena is possible. A layer showing up in area C5 might be aerosol or a water layer with a small fraction of ice particles. These mixed-phase clouds occur frequently in the Arctic (Intrieri et al., 2002).

The statistical results for the different altitude intervals are given in Table 4 . Within the analyzed $145 \mathrm{~h}$ of data, the fraction where neither enhanced backscatter nor volume depolarization was observed (C1) increases with height as well as 
KARL: VD vs. BSR 532 - 8 March 2007, 15:43 - 16:17 UTC

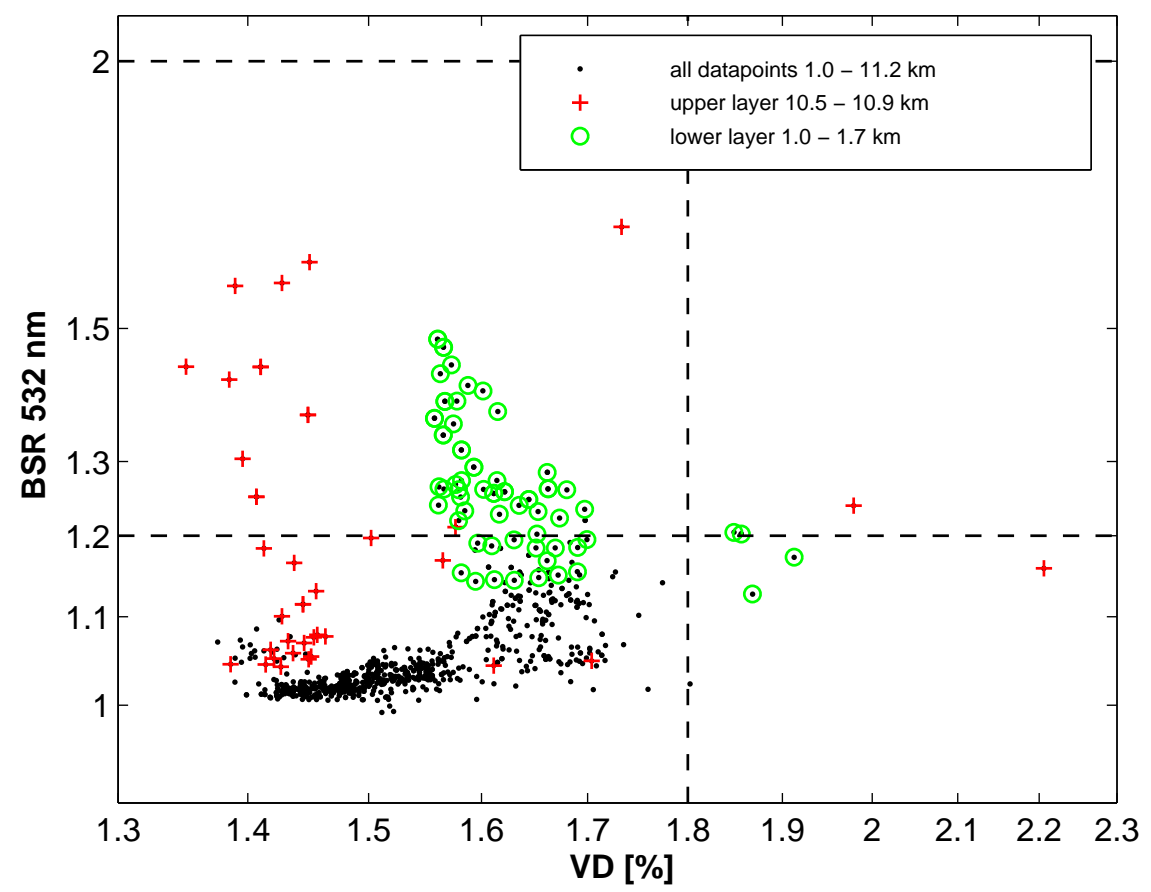

Fig. 9. VD vs. BSR for different layers and time frames on 8 March 2007.

the ice cloud fraction $(\mathrm{C} 7-\mathrm{C} 10)$ up to $8 \mathrm{~km}$. Depolarization without noticeable backscatter (C4) makes up a third within the lowest $6 \mathrm{~km}$. Water clouds (C2), aerosols (C5/C6) and water clouds with a certain ice cloud fraction (C3-C6) decrease with height. With reference to the total number of detected clouds, pure water clouds (C2 1-7 km) account for $2.8 \%$, mixed-phase clouds and aerosols (C3-C5 1-7 km) account for $70.0 \%$ and the ice cloud fraction (C3-C5 7-12 km and C7-C10 1-12 km) contributes to $27.2 \%$. Although our system is not suitable for measuring thick clouds and hence they are not included in the statistics, this corresponds very well with the value of $73 \%$ of clouds containing water found by Intrieri et al. (2002) during the SHEBA experiment.

Table 5 shows the scattering characteristics according to different flow patterns. As shown in Sect. 2.2, the ASTAR campaign was characterized by air masses mainly coming from the Canadian Arctic, while within the whole two months period, flow from Eurasia was much more frequent. All KARL profiles for the corresponding clustered trajectories between 2 and $4 \mathrm{~km}$ altitude were analyzed with regard to their scattering characteristics. For trajectories originating in the Canadian Arctic, the fraction of clear sky measurements $(\mathrm{BSR}<1.2)$ was significantly lower than for the Eurasian clusters, where the thin aerosol fraction was significantly increased, as expected in the Arctic Haze season. The ice cloud and water cloud fraction does not differ, while for Canadian air masses $\mathrm{C} 4$ is enhanced at the expense of $\mathrm{C} 1$, European air masses show opposite characteristics.

\section{Case studies with KARL}

Within this section case studies supporting our classification scheme are given using the KARL data of five particular days with interesting cloud and aerosol structures (cf. Table 3). The cases $\mathrm{C} 1$ and $\mathrm{C} 4$ are not considered as there is no enhanced backscatter. Two more case studies observed with KARL during ASTAR 2007 are described in Lampert et al. (2009), an optically very thin low level liquid layer on 19 April and a multi layered ice cloud with varying LR on 21 April.

\subsection{Low and medium depolarization C2, C3, C5 and C6}

Layers with comparably low depolarization were observed on 8 March in $10.5 \mathrm{~km}$ and $1.5 \mathrm{~km}$, on 13 March and 15 March in $2.8 \mathrm{~km}$ and $3.2 \mathrm{~km}$ respectively and on 7 April at a temperature inversion in $0.6 \mathrm{~km}$ altitude.

The lower layer on 8 March was observed from 14:45 to 16:50 UTC, the upper layer is presented within the same time frame although it persisted longer. Noticeable in the scatter plot Fig. 9 is the very low volume depolarization of below $1.8 \%$ for almost the whole altitude range, which, in combination with enhanced backscatter, suggests the existence of spherical scatterers. The balloon sounding at 11:00 UTC showed enhanced relative humidity of 70 to $80 \%$ within the lower layer and around $50 \%$ for the upper layer (the relative humidity over ice was ca. $85 \%$, respectively), which probably increased in the afternoon to enable cloud formation. 


\section{KARL: BC 532 \& VD - 8 March 2007}
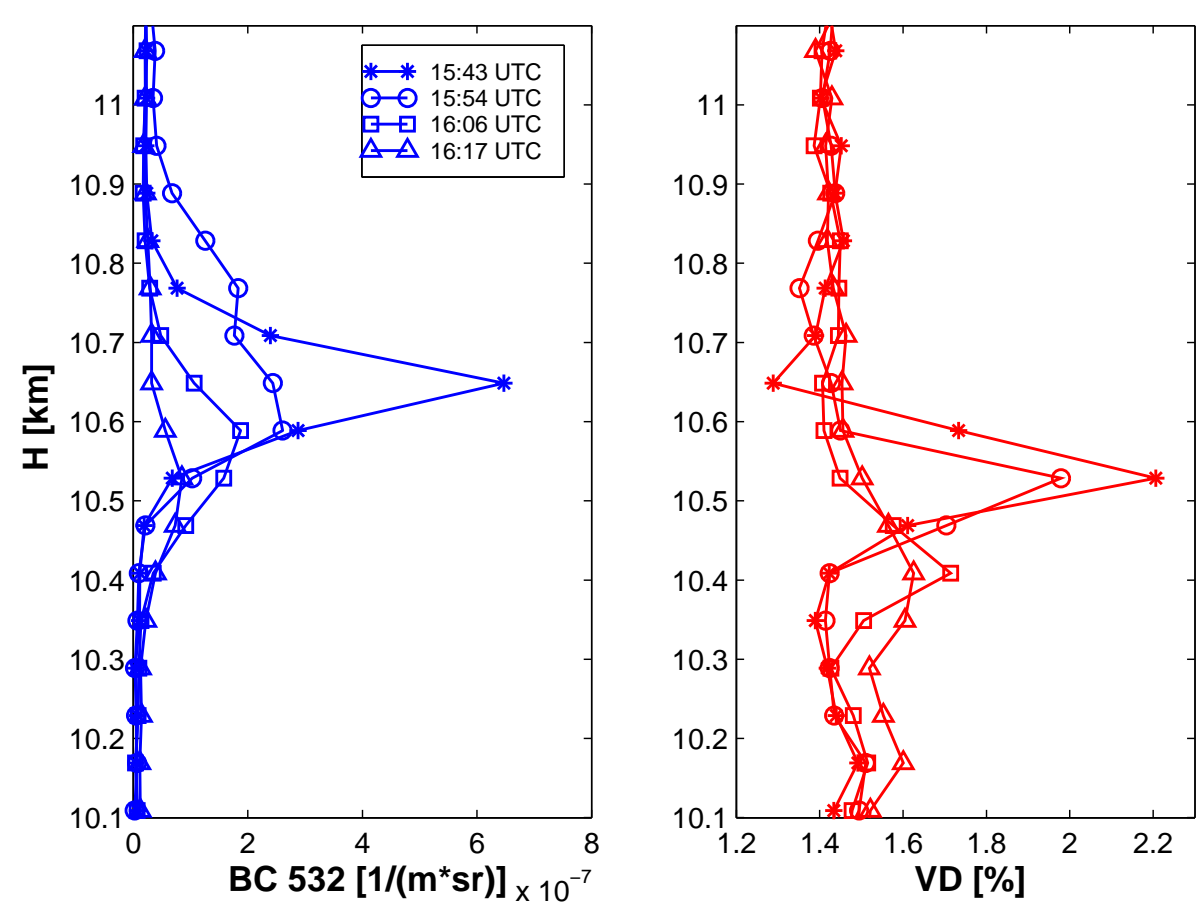

Fig. 10. Temporal evolution of BC (532 nm) and VD profiles from 15:43 to 16:17 UTC on 8 March 2007.

The color ratio $\mathrm{CR}$ was determined to be around 1 for the lower layer, which leads to the assumption of rather big particles compared to the wavelength (Ansmann et al., 2003), indicating a subvisible water cloud layer. This independence of backscatter with wavelength is a typical result for cloud particles larger than $5 \mu \mathrm{m}$ (van de Hulst, 1981).

Within the higher layer the temperature during the radio sounding was below $210 \mathrm{~K}$, prohibiting the existence of fluid water droplets. Very low depolarization values for ice particles can be observed for ice plates that are oriented horizontally (Hu et al., 2007; Reichardt et al., 2002). The lowest part of the ice cloud (10.4-10.5 km) showed a slightly higher depolarization (see Fig. 10). A feasible explanation would be a less perfect orientation of the plates than in the layer above. The lidar ratio of the ice cloud could be determined to $10 \mathrm{sr}$ which leads to an optical depth of 0.001 , close to our detection threshold of $1.2 \times 10^{-4}$.

The scatter plots for the low cloud layers on 13 and 15 March are shown in Figs. 11 and 13, respectively. The layer under consideration is marked in green.

On 13 March at 16:00 UTC the formation of a cloud layer could be observed. As can be seen in Fig. 12, at 15:47 UTC very little backscattering with no depolarization between 2.8 and $3.0 \mathrm{~km}$ occurred. At 16:00 UTC the layer intensified between 2.7 and $3.0 \mathrm{~km}$ while the depolarization increased to about $3 \%$ in a lower layer at $2.6 \mathrm{~km}$. During the next $45 \mathrm{~min}$, $\mathrm{BC}$ persisted at $3 \times 10^{-5}$ between 2.6 and $3.0 \mathrm{~km}$ while the
VD values between 2.2 and $2.6 \mathrm{~km}$ increased to above $15 \%$. This cloud obviously evolved as a two-layer structure with spherical water droplets in the top layer and depolarizing ice crystals below. From 15:35 to 16:11 UTC, the aerosol optical depth in the visible, calculated with $L R=18$ sr increased gradually from 0.002 to 0.10 within the water layer while it only slightly increased within the ice layer (from 0.002 to 0.01 ). For the optically thicker water layer, the evolution of the Ångström exponent for backscattering decreased from 1.3 at 15:35 to essentially zero at 16:11 UTC. Hence, we were able to observe the growth of spherical water droplets in the top layer as have been reported by Pinto (1998) and Shupe et al. (2008).

The further temporal evolution shows the formation of a pure ice layer which is studied in further detail in Sect. 4.2.

On 15 March, during the radio sounding at 11:00 UTC three distinct layers with completely different characteristics could be observed (see Fig. 14). The two lower layers show similar values for $\mathrm{BC}\left(2 \times 10^{-7}\right)$ with the middle layer featuring slightly more depolarization. Nevertheless, both layers are assumed to consist of spherical particles since depolarization is below $4 \%$. The main difference between these two layers is the humidity. In Fig. 14 the radiosonde data is compared to the backscatter and depolarization profiles at 11:20 UTC. The relative humidity between 4 and $7 \mathrm{~km}$ is not higher than $30 \%$ which prohibits the formation of water clouds (see Sect. 3.3.2). Therefore this layer is assumed to 


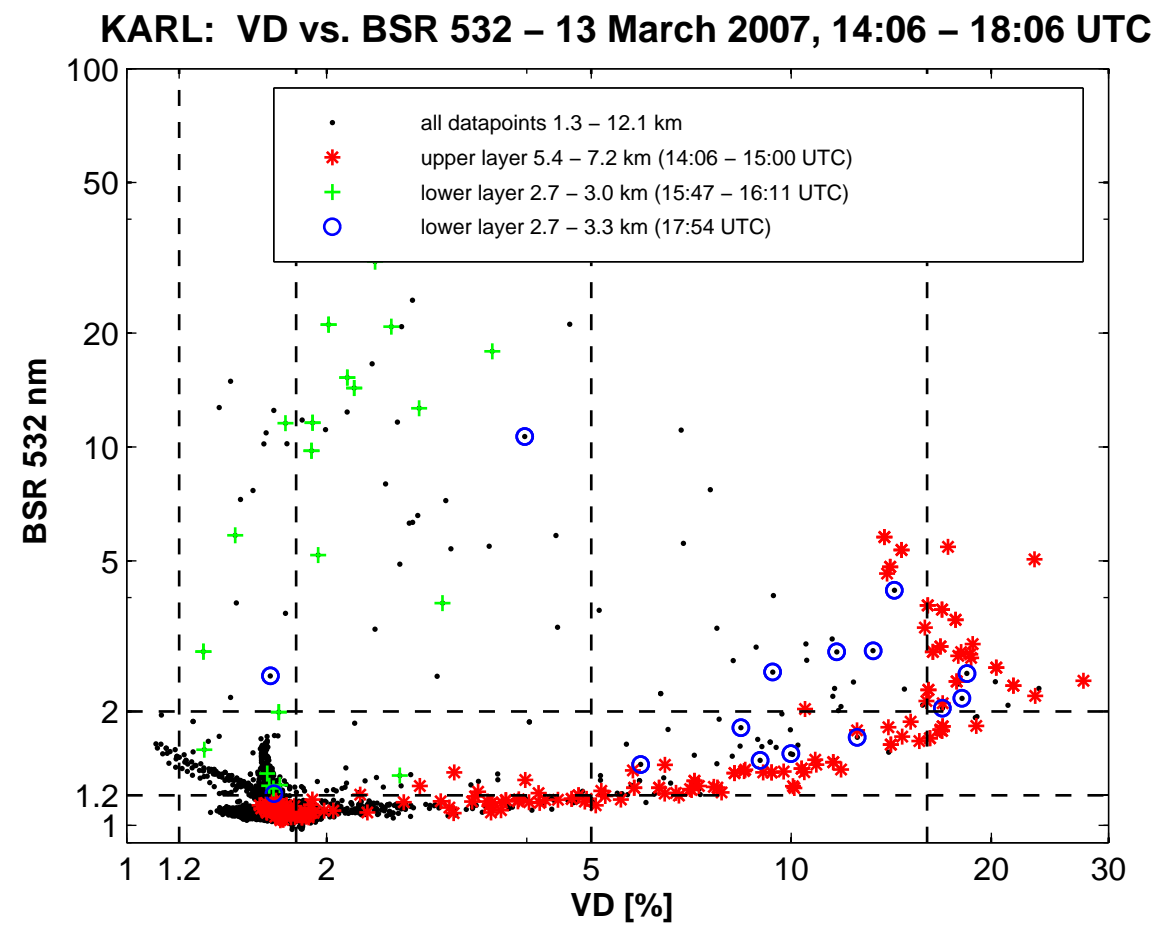

Fig. 11. VD vs. BSR for different layers and time frames on 13 March 2007.

\section{KARL: BC 532 \& VD - 13 March 2007}
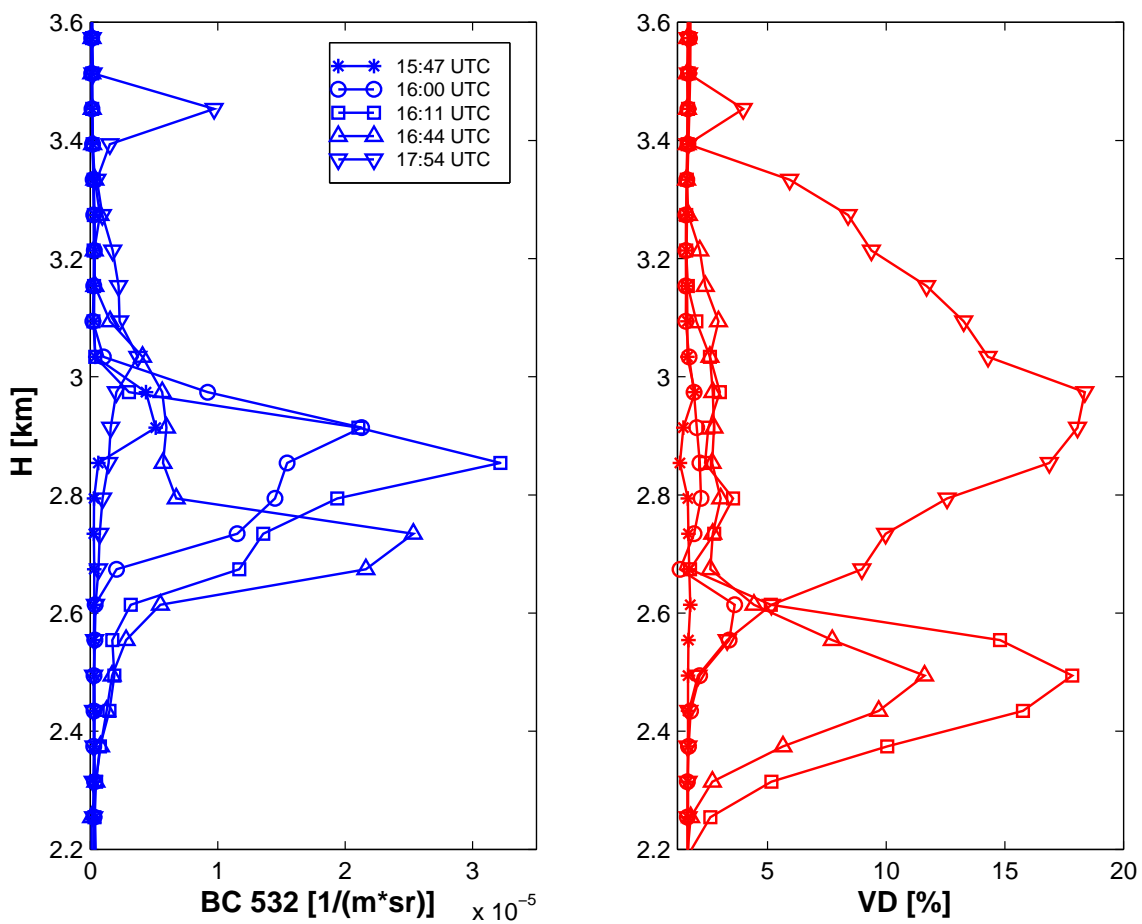

Fig. 12. Temporal evolution of BC (532 nm) and VD profiles from 15:47 to 17:54 UTC on 13 March 2007. 


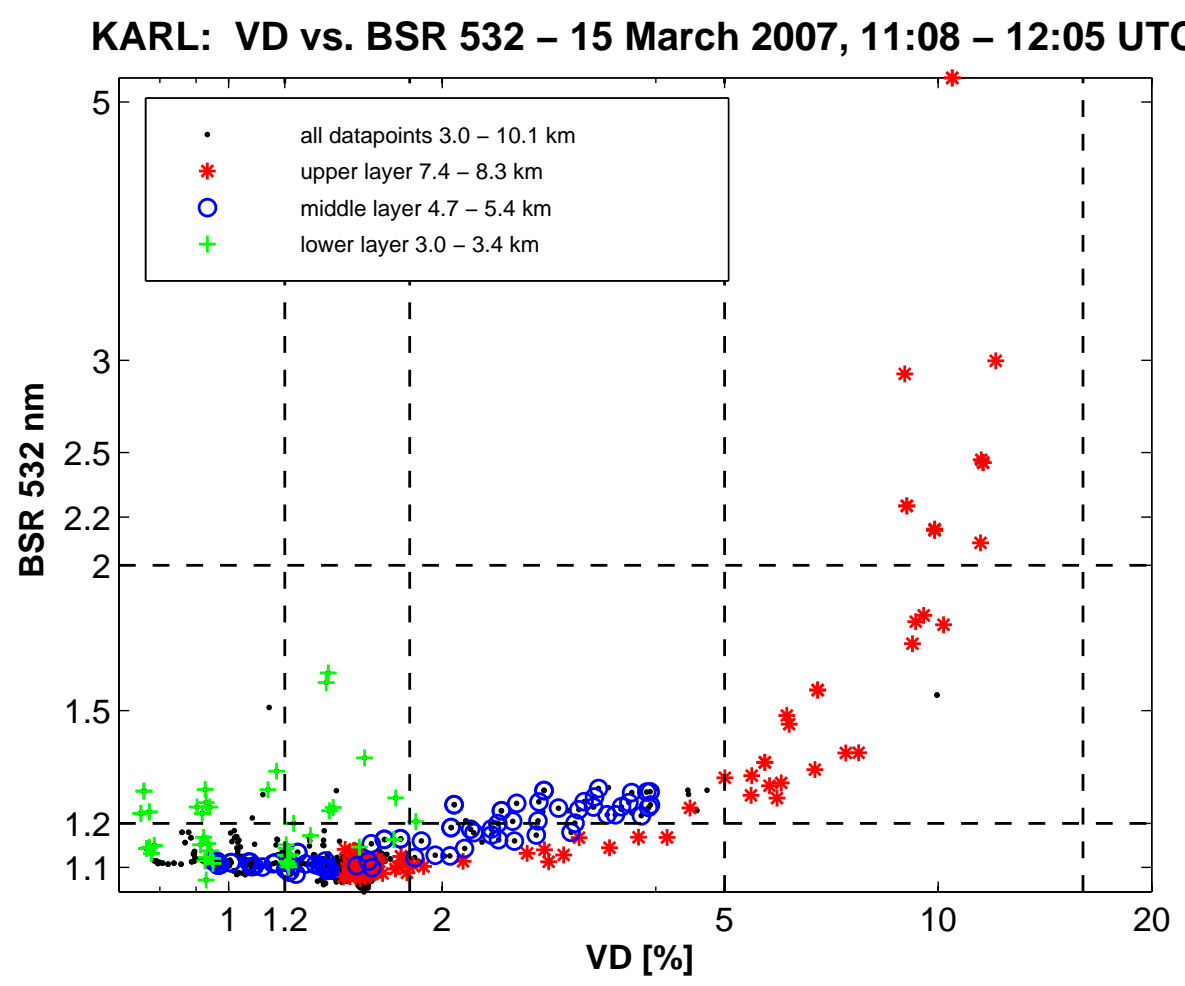

Fig. 13. VD vs. BSR for different layers and time frames on 15 March 2007.

consist of aerosol particles and will be further discussed in Sect. 4.3. Within the lower layer however, the relative humidity measured with the temporally close radio sounding was determined to be higher than $80 \%$ and a reduction in the temperature gradient just above the cloud in 3.4 to $3.6 \mathrm{~km}$ altitude occurred, probably separating two different air masses.

On 7 April, simultaneously to the launch of a RS-92 sonde, a short living low level subvisible cloud was detected in a temperature inversion around $600 \mathrm{~m}$ altitude. The boundary layer cloud occurred at $255.5 \mathrm{~K}$ in a temperature inversion of $1.5 \mathrm{~K}$. The RS 92 measured $82 \%$ relative humidity, corresponding to $98 \%$ relative humidity over ice. Figure 16 depicts profiles of $\mathrm{BC}$ and VD and Fig. 15 the corresponding scatter plot. The low depolarization of some $2 \%$ is slightly higher than for a pure water cloud but too low for most ice crystals. As observed earlier, the layer of highest depolarization lies geometrically $100 \mathrm{~m}$ below the maximum backscatter. If we assume that some liquid water is mixed into this cloud which formed exactly at saturation then in the cloud the water mixing ratio must have been $22 \%$ higher or the temperature $2.35 \mathrm{~K}$ lower than measured by the sonde (Fig. 16), which would be an unusually high deviation. As the cloud persisted for about $20 \mathrm{~min}$ (see Fig. 17) with a wind speed of $4 \mathrm{~m} / \mathrm{s}$ this wet patch had an extent of ca. $5 \mathrm{~km}$. Unfortunately, the low altitude of this subvisible cloud results in an incomplete overlap. Hence, it was not possible to calculate its extinction. The presented backscatter and volume depo- larization values are ratios of lidar profiles and therefore not so strongly affected by incomplete overlap. Calculating BC for $355 \mathrm{~nm}$ and $532 \mathrm{~nm}$ by the ratio between the elastic and the $N_{2}$ Raman-shifted returns (Ansmann et al., 1992), the color ratio was determined to be unity. Therefore we assume rather large particles, which contrasts to an otherwise similar liquid subvisible cloud layer on 19 April described in Lampert et al. (2009) in this issue.

\subsection{High depolarization $\mathrm{C} 7-\mathrm{C} 10$}

Highly depolarizing air masses were observed in the upper troposphere on 13 March and 15 March, on 13 March the formation of a low level, depolarizing ice cloud could be observed as well (as indicated in Sect. 4.1).

From the start of the measurements on 13 March at 14:00 UTC until about 14:50 UTC an ice cloud structure between 6 and $8 \mathrm{~km}$ was observed. Its depolarization shows values of up to $20 \%$ while the backscatter values are relatively low (see Fig. 11). With an estimated lidar ratio of $18 \mathrm{sr}$ the optical depth at 14:17 UTC was calculated to 0.035 , which is almost subvisible (Lynch et al., 2002).

Contemplating the temporal evolution of the lower layer, already described in Sect. 4.1, one observes an interesting transition between 17:30 and 17:50 UTC. As can be seen in Fig. 12, the backscatter coefficient decreases by a factor of about 4 while the depolarization increases to up to $18 \%$. This 


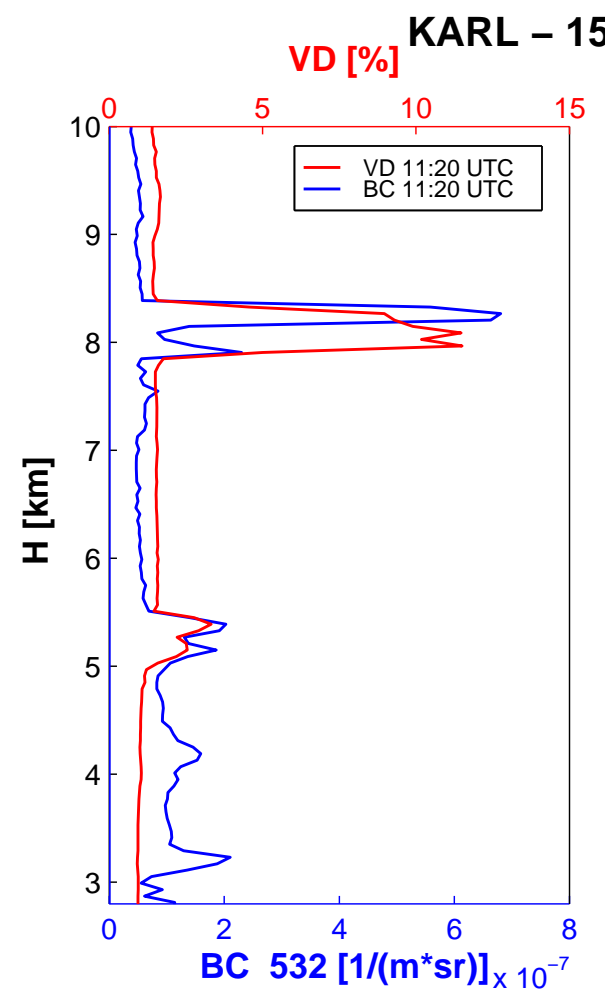

$\mathrm{RH}[\%]$

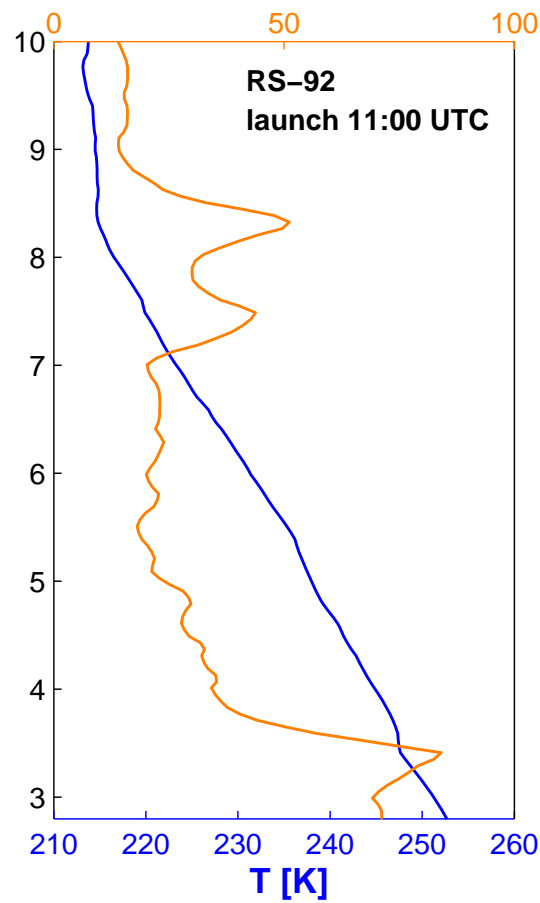

Fig. 14. Left: $\mathrm{BC}(532 \mathrm{~nm})$ and VD profiles at 11:20 UTC on 15 March 2007, right: $\mathrm{T}$ and RH profiles from the radiosonde launch at 11:00 UTC on 15 March 2007.

KARL: VD vs. BSR 532 - 7 April 2007, 07:54 - 16:53 UTC

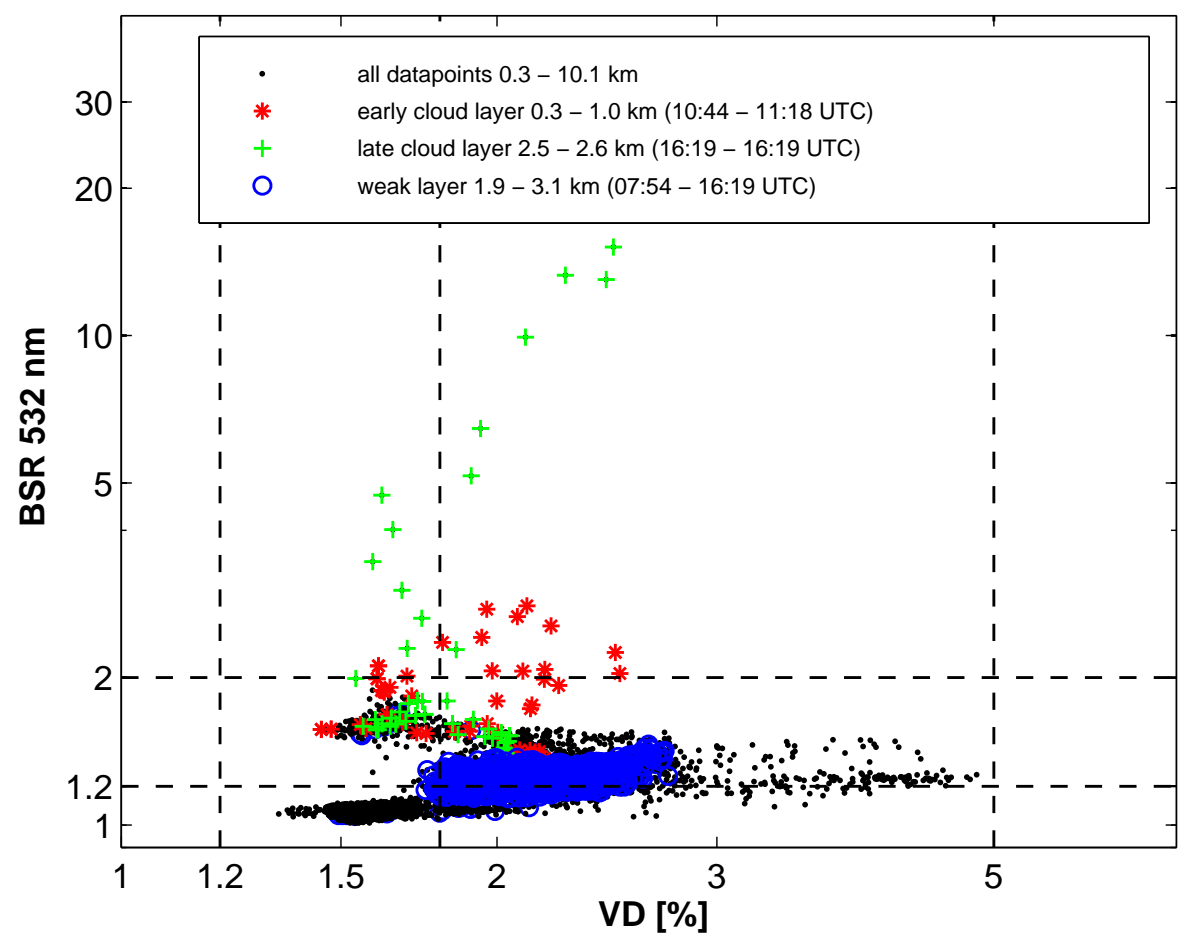

Fig. 15. VD vs. BSR for different layers and time frames on 7 April 2007. 

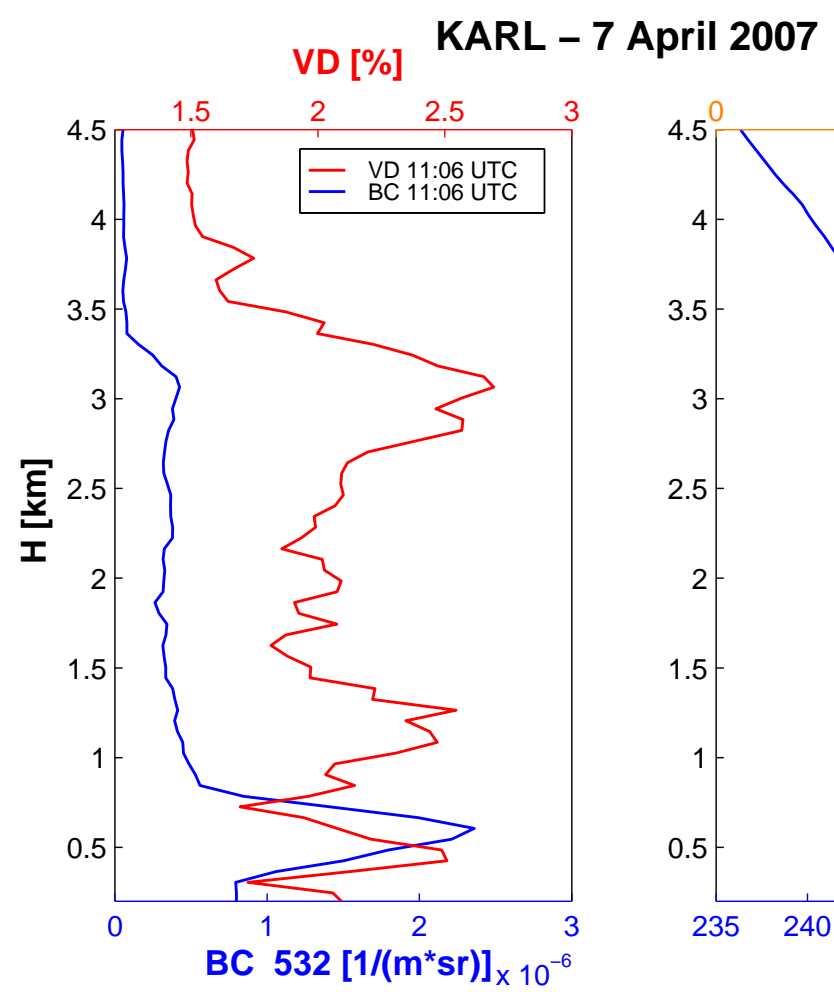

$\mathrm{RH}[\%]$

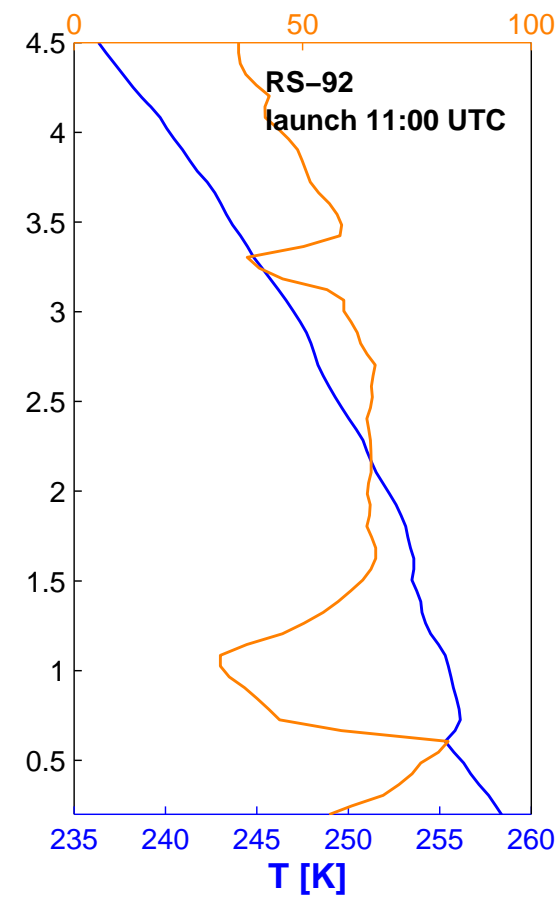

Fig. 16. Left: BC (532 nm) and VD profiles at 11:06 UTC on 7 April 2007, right: T and RH profiles from the radiosonde launch at 11:00 UTC on 7 April 2007.

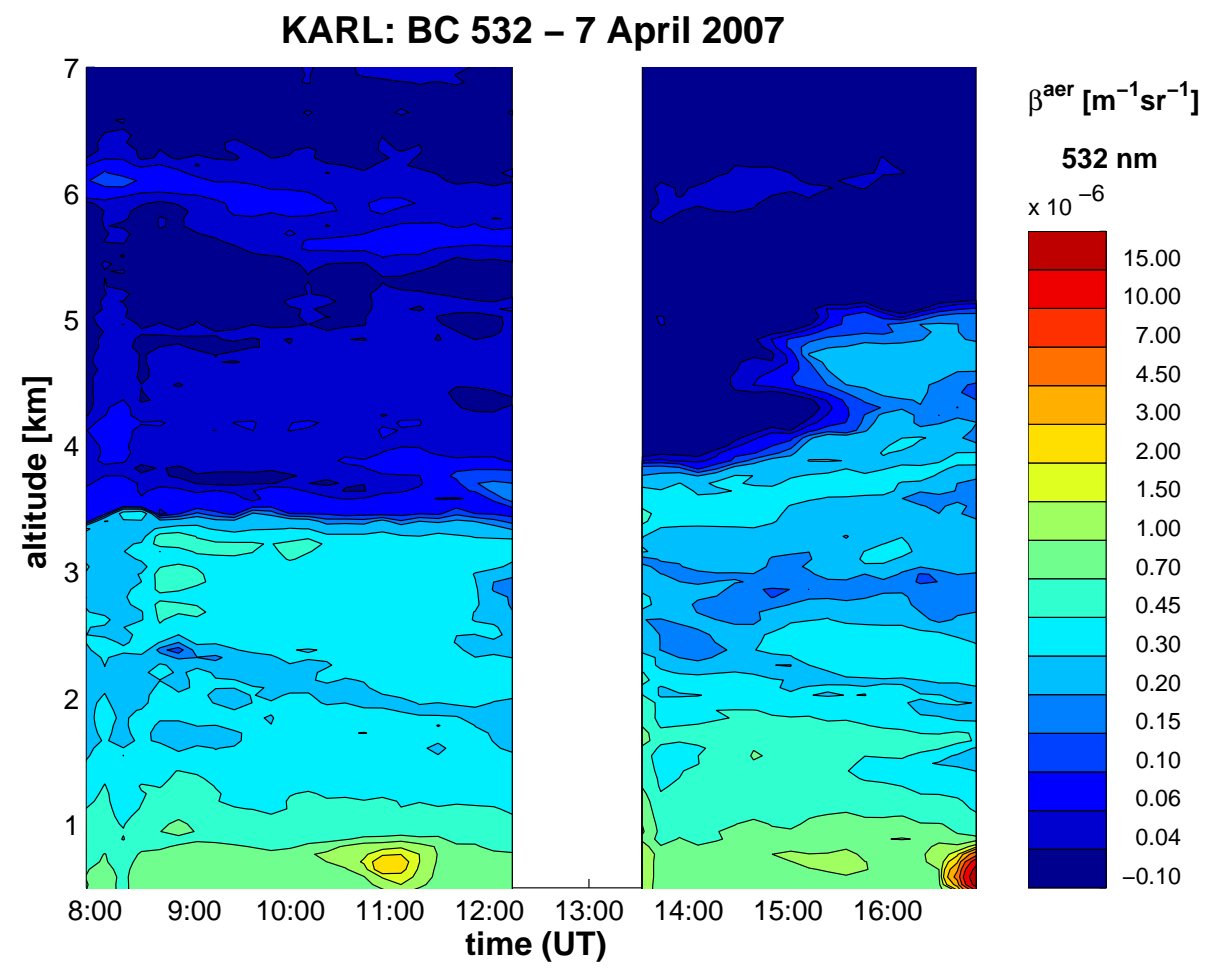

Fig. 17. Temporal evolution of BC (532 nm) profiles on 7 April 2007. 


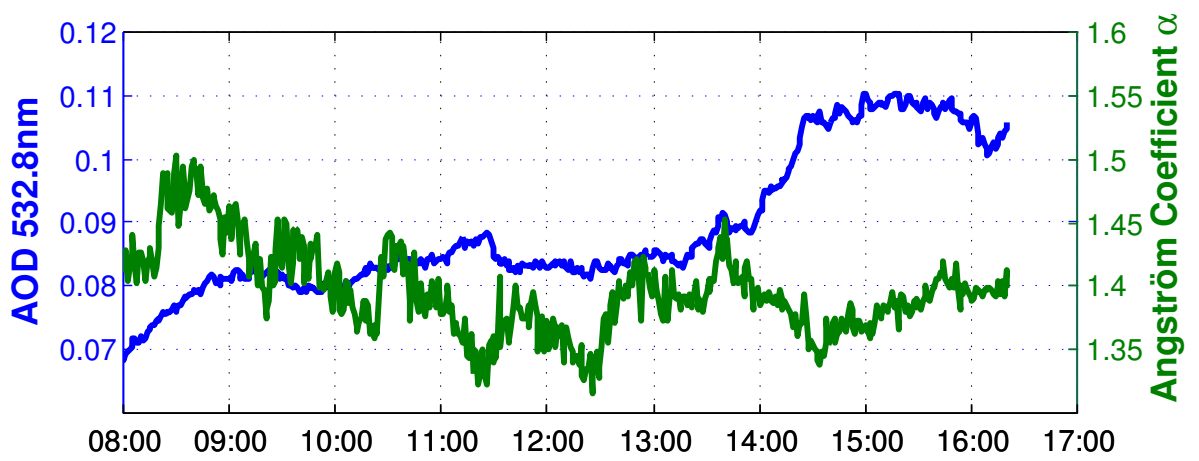

Fig. 18. AOD (532 nm) and Ångström exponent $\alpha$ derived from photometer measurements on 7 April 2007.
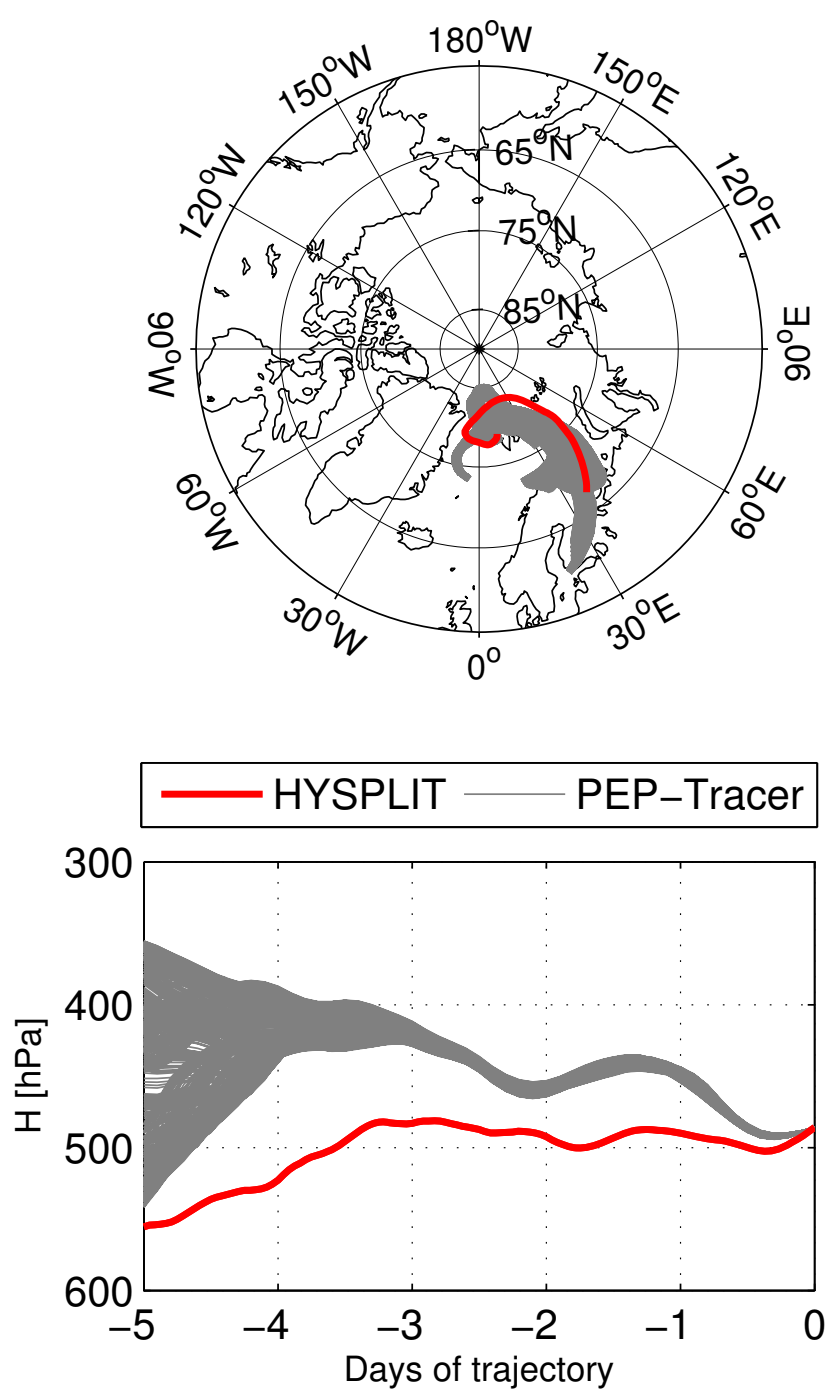

Fig. 19. 5-day backward trajectories for an aerosol layer on 15 March 2007 at 11:00 UTC, calculated with the PEP-Tracer (ensemble of 1000 trajectories) and NOAA HYSPLIT model. can no longer be a water layer and thus, we observed a glaciation process. Supporting this theory, the temperature in this layer, measured during a radio sounding at 10:48 UTC, was about $250 \mathrm{~K}$. Due to the decreasing backscatter coefficient the layer's AOD also decreases to about 0.02 at 17:55 UTC. The accumulated ice cloud layer has similar scattering characteristics as the first observed cirrus layer as can be seen in the scatter plot Fig. 11.

Depolarization values of up to $12 \%$ were obtained for the high cloud layer on 15 March between 7.4 and $8.8 \mathrm{~km}$ altitude at 14:06 UTC when the observation started. During the radio sounding at 11:00 UTC the relative humidity over ice in this layer was well above $50 \%$. Within the following one hour the ice cloud layer completely disappeared and the respective AOD decreased from 0.03 to 0.002 , hence we observed a very thin, short living cloud structure.

\subsection{Aerosols C5-C6}

During March 2007, two weak aerosol events (C5) were observed, while in April not even weak aerosol could be definitely identified. For the Mie code analysis of these aerosol cases all three elastic and both inelastic (387 $\mathrm{nm}$ and $607 \mathrm{~nm}$ ) channels had to be considered according to Ansmann et al. (1992). The trajectory calculations in this chapter were performed with the PEP-Tracer and the HYSPLIT model (Orgis et al., 2009; Draxler and Hess, 1998). The first one uses ensemble calculations and hence provides uncertainty information; the latter one was used to obtain information on precipitation along the trajectory.

A persistent aerosol layer was observed from 14 March 20:40 UTC to the end of the observation at 15 March 12:40 UTC, due to the formation of the low cloud described in Sect. 4.1. The weak layer was observed in around $6 \mathrm{~km}$ altitude sinking to $5.3 \mathrm{~km}$, and the corresponding air trajectories suggest an origin of the air masses in central Europe (see Fig. 19). It stands out due to its long lifetime, its considerable altitude - the majority of Arctic Haze events occur in the lower free troposphere over Spitsbergen (Scheuer et al., 2003) - its quite high depolarization of 5\% and the 


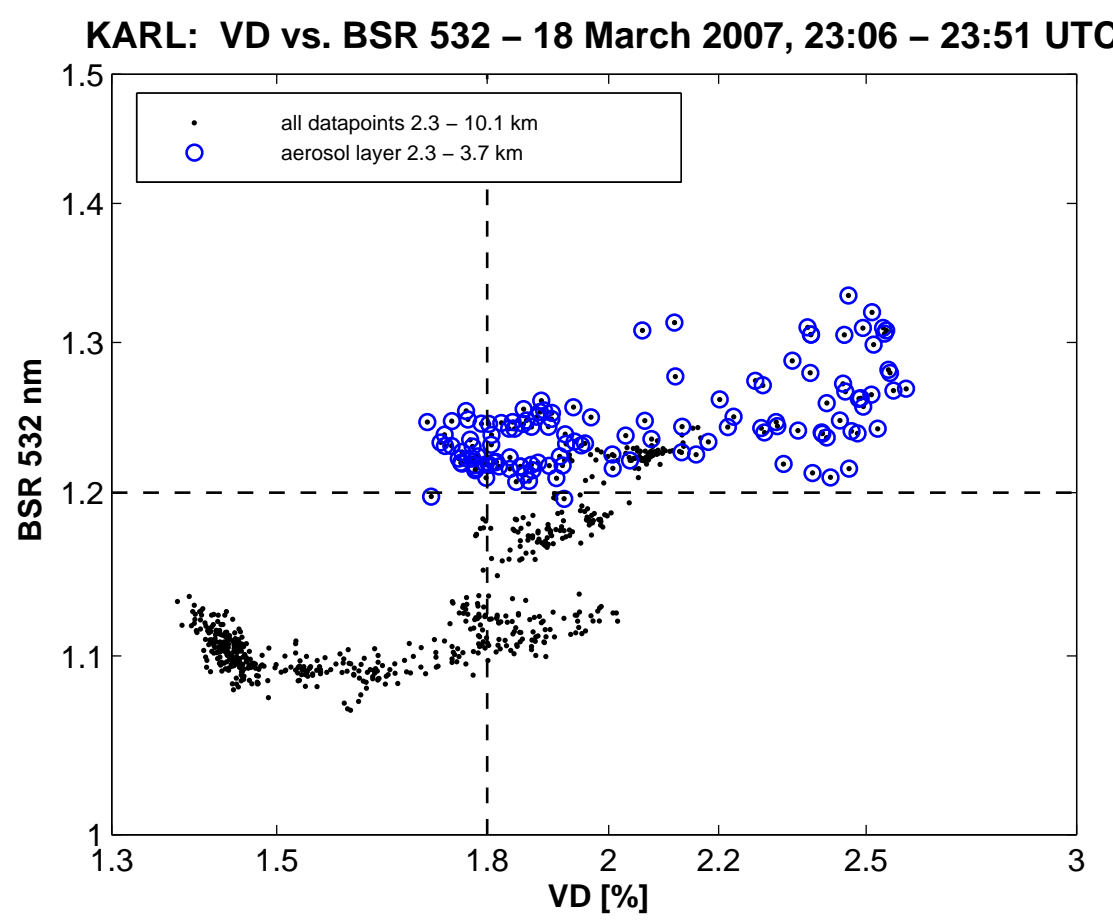

Fig. 20. VD vs. BSR for different layers and time frames on 18 March 2007.

considerable amount of precipitation of more than $20 \mathrm{~mm}$ which occurred in these air masses prior to their arrival. Nevertheless in the scatter plot in Fig. 13 the layer can clearly be distinguished from the cloud layer below. As can be seen in radiosonde data from 15 March 11:00 UTC in Fig. 14, the arriving air masses were with $35 \%$ relative humidity far too dry for cloud formation and the derived lidar ratios of $64.3 \mathrm{sr}$ for the $532 \mathrm{~nm}$ channel and $39.6 \mathrm{sr}$ for $355 \mathrm{~nm}$ seem to be too high for clouds. The maximum AOD of this layer of 0.025 for the UV and 0.01 for the visible occurred around 01:00 UTC on 15 March. As the VD values are still quite low we neglect the particles asphericity and perform an inversion of the lidar data with Mie theory according to Böckmann (2001). As a result, an index of refraction of $n=1.6-0.011 i$, a mono-modal log-normal size distribution of 93 particles per ccm $( \pm 50 \%)$, effective radius $r_{\text {eff }}=0.199 \mu \mathrm{m}( \pm 50 \%)$ and a distribution width of $\sigma=1.58( \pm 10 \%)$ were found. These seem to be appropriate values for a sulphate soot mixture, the main constituents of Arctic Haze (Yamanouchi et al., 2005).

Due to the uncertainty of backward trajectories in the Arctic after more than 5 days it seems impossible to ascribe this event to a precise cause or location (see Fig. 19). From the wind speed of $4.5 \mathrm{~m} / \mathrm{s}$ in $6 \mathrm{~km}$ altitude from the sounding on 15 March, we estimate that even in the unlikely case that the aerosol event stopped directly after the end of our lidar observations, it had a horizontal extent of at least $260 \mathrm{~km}$. On the other hand its vertical extent never exceeded $900 \mathrm{~m}$ and over more than $50 \%$ in time it was as small as $300 \mathrm{~m}$.
Another weak Arctic Haze event occurred in the night from 18 to 19 March 2007. As can be seen in Fig. 20, the backscatter ratio around $3 \mathrm{~km}$ altitude is enhanced. At $2.5 \mathrm{~km}$ a clear maximum of the extinction can be seen in both $\mathrm{N}_{2} \mathrm{Ra}$ man channels which yield to lidar ratios of $80 \mathrm{sr}( \pm 12 \mathrm{sr})$ at $532 \mathrm{~nm}$ and $60 \mathrm{sr}( \pm 10 \mathrm{sr})$ at $355 \mathrm{~nm}$. These values are higher than the lidar ratios obtained at different haze events over the site. Based on our (so far still partially unpublished) data the Arctic Haze typically has a lidar ratio of $40-60 \mathrm{sr}$ at $532 \mathrm{~nm}$ and $30-50 \mathrm{sr}$ at $355 \mathrm{~nm}$. However, the lidar ratio seems to be almost always about $25 \%$ higher at $532 \mathrm{~nm}$. The layer of increased extinction and backscatter coincides with an increase of depolarization from $2 \%$ to $2.5 \%$.

The result of the inversion with Mie code gives a refractive index of $n=1.56-0.01 i$ and the aerosol can best be described by a one-modal log-normal distribution with 343 particles per ccm $( \pm 30 \%)$, effective radius $r_{\text {eff }}=0.177 \mu \mathrm{m}( \pm 10 \%)$ and a distribution width of $\sigma=1.59( \pm 10 \%)$ which is similar to the 15 March case. The corresponding PEP-Tracer and HYSPLIT trajectories are shown in Fig. 21. The trajectories find a relation between Russian origin and the arrival of air masses over Ny-Ålesund at $2.5 \mathrm{~km}$ altitude. Given the sparse meteorological data in the high Arctic we consider this as justifiable. No precipitation occurred out of the trajectory, so that an uptake of aerosol over Russia seems possible.

On 7 April 2007 an increased AOD was measured by the photometer as summarized in Fig. 18. It shows the aerosol optical depth at $532.8 \mathrm{~nm}$ and the Ångström exponent. During the time period observed with lidar, the optical depth 

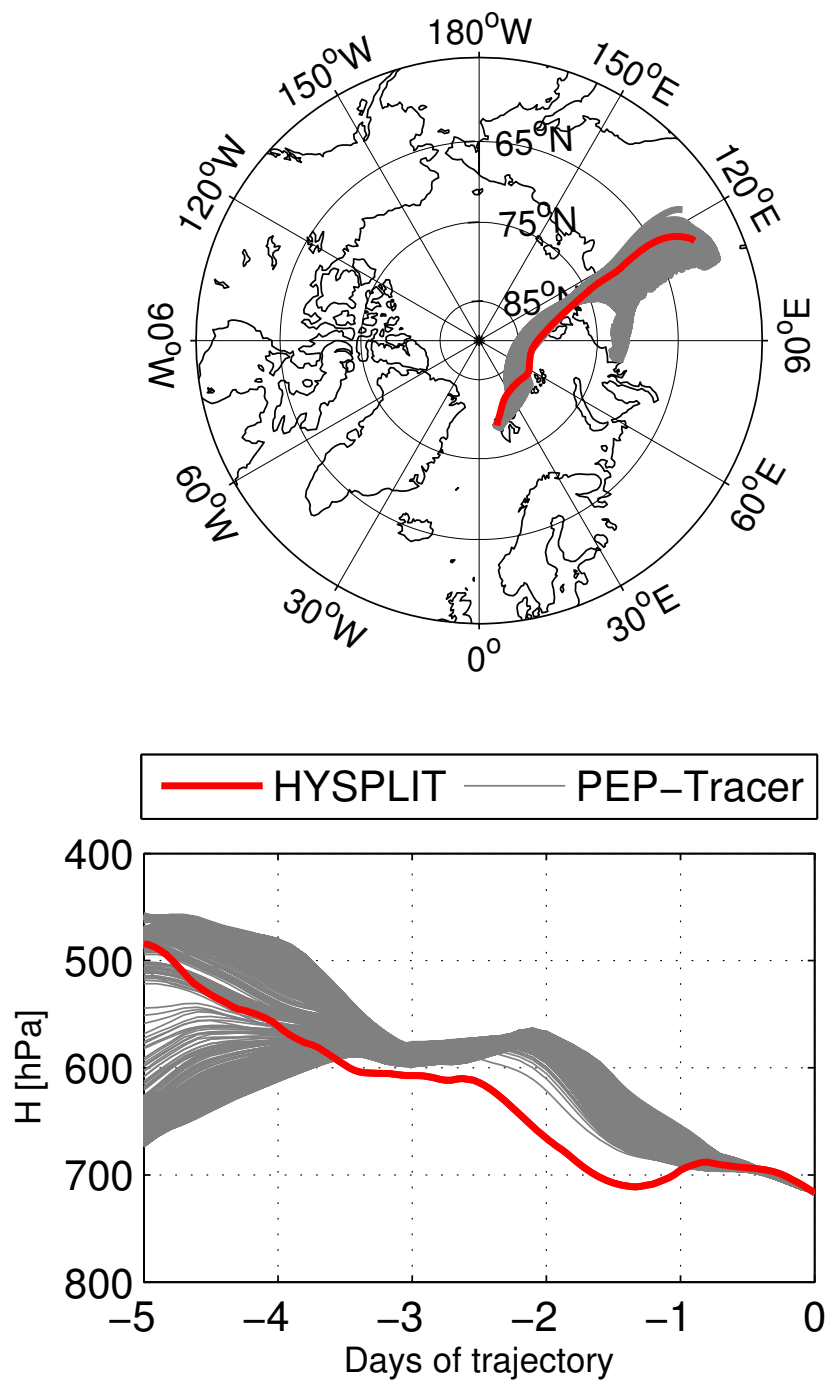

Fig. 21. 5-day backward trajectories for an aerosol layer on 19 March 2007 at 00:00 UTC, calculated with the PEP-Tracer (ensemble of 1000 trajectories) and NOAA HYSPLIT model.

increases without any change in the particle size. Hence, the increase of AOD is predominantly due to an increase of number concentration of particles with the same size. Generally the air mass did not change significantly, which is supported by the backward trajectories which came from European Russia. The value of the Ångström exponent is more "aerosol-like" the whole day and does not show any contamination with super-micron particles. The short living cloud at 11:00 UTC described in Sect. 4.1 is invisible in the sun photometer data because lidar and photometer are looking in different directions at our polar site. An inversion of the photometer AOD as well as the phase function of scattering derived an index of refraction of 1.4 which is lower than expected for the sulfate-soot mixtures of Arctic Haze (Yamanouchi et al., 2005) which typically show a refractive index of 1.5 or higher (Ritter et al., 2004). The low index of
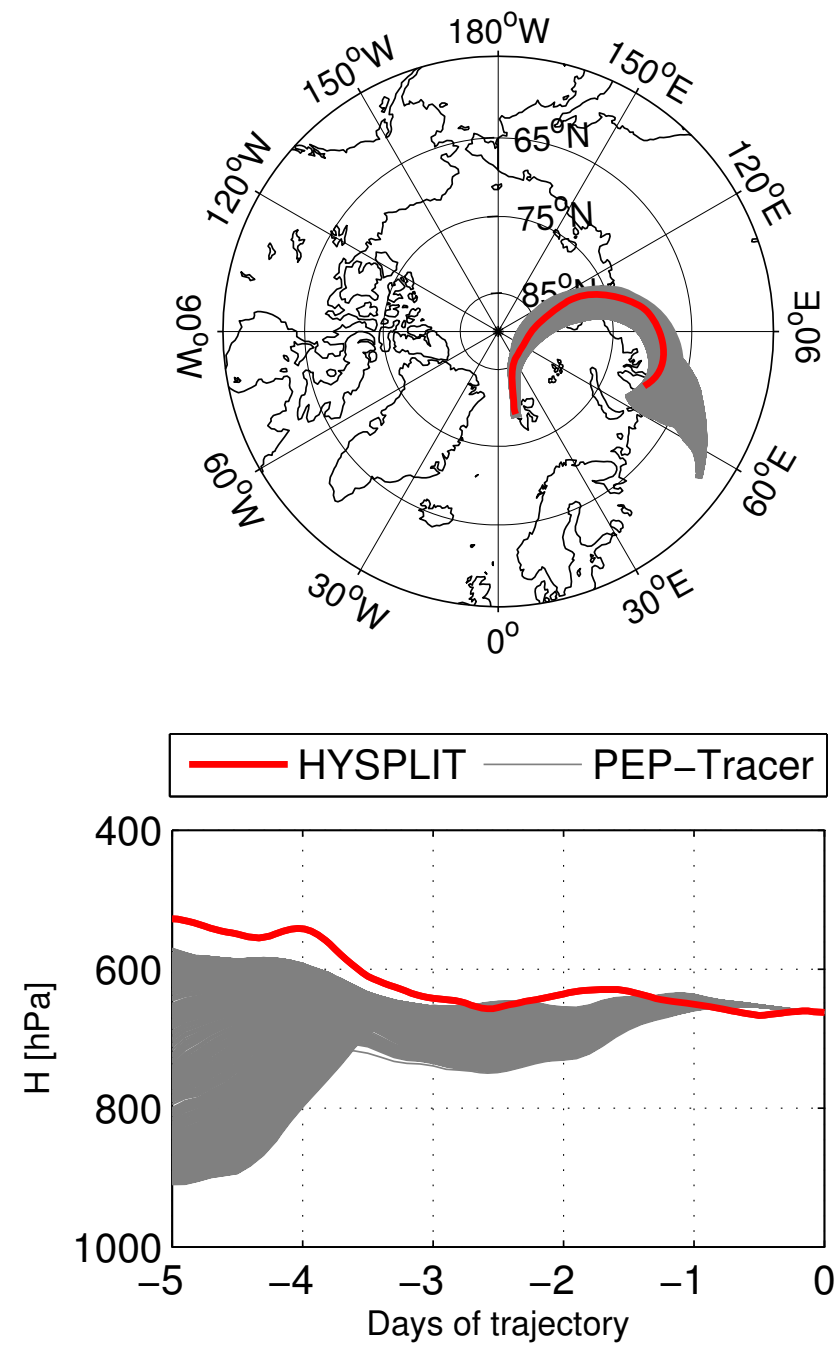

Fig. 22. 5-day backward trajectories for air masses on 7 April 2007 at 11:00 UTC, calculated with the PEP-Tracer (ensemble of 1000 trajectories) and NOAA HYSPLIT model.

refraction was confirmed by an inversion of the lidar data at several times during that day, although, unfortunately the inversion of a size distribution turned out to be numerically unstable. This might at least partly be explained by the weakness of the $\mathrm{N}_{2}$ Raman channel on that day. Moreover the scatter plot (Fig. 15) does not find any differences in the afternoon as the AOD increases above 0.1 compared to the cleaner morning. The radiosonde measured a slightly increased humidity in this $4 \mathrm{~km}$ altitude region and the PEP-Tracer and HYSPLIT back-trajectories showed air masses coming from Russia (see Fig. 22) without precipitation. Nevertheless, Arctic Haze or at least absorbing components as the cause of this increased optical depth seem to be unlikely. Probably small water droplets and ice crystals, which extend up to $6.4 \mathrm{~km}$ altitude in the afternoon (as can be seen in Fig. 17), possibly mixed with an insoluble aerosol component, gave rise to the AOD increase presented here. 
This example clearly shows that "increased optical depth with low Ångström exponent and air mass from Russia" alone is not sufficient to adequately characterize the polar troposphere. Moreover it emphasizes the need for future combined in situ and remote sensing campaigns to fully describe aerosol cloud interactions especially in humid air.

\section{Conclusions}

In this work a statistics of the observations of (thin) clouds and aerosols at a site in the high European Arctic has been presented.

During March and April 2007, temperature and relative humidity were observed performing 71 balloon soundings. Temperature inversion layers occurred frequently - surfacebased as well as in up to $2.5 \mathrm{~km}$ altitude due to the orography of nearby mountains.

Statistics of the altitude dependent cloud cover from the MPL lidar has been presented, showing maximum cloud cover between 2 and $3 \mathrm{~km}$. The overall cloud cover was determined to be $73 \%( \pm 5 \%)$ which is a little bit less than other ground based retrievals for the site (Shiobara et al., 2003) and other Arctic locations. From the comparison of MPL data with radiosondes, we found some cases with relative humidity down to $60 \%$ sufficient for cloud existence especially in altitudes above $4 \mathrm{~km}$. Hence a dry bias of the RS-92 in extreme environments must be considered, similar to the findings of Rowe et al. (2008).

The $145 \mathrm{~h}$ lidar data obtained with our Raman lidar KARL refer to clear conditions with only thin cloud structures and aerosol layers. Case studies were performed for five different days, featuring the wide variety of Arctic clouds and aerosols. On 8 March a low $(1.0-1.7 \mathrm{~km})$, very weak and hence subvisible water cloud layer was observed simultaneously with a very high non-depolarizing ice cloud, presumably consisting of horizontally oriented ice plates. A boundary layer cloud at a temperature inversion was observed on 7 April 2007 while on 13 March 2007 the transformation of a low level mixed phase cloud with a liquid layer on top to a pure ice cloud could be observed. Thin high level ice clouds with high volume depolarization as on 13 March and 15 March 2007 occurred frequently. On 15 and 18 March 2007, Arctic Haze layers with a refractive index of $n=1.6-0.01 i$ were observed.

Being able to run the KARL whenever possible during March and April 2007, we successfully performed statistics where we classified the different cloud and aerosol structures according to their scattering properties VD and BSR. Ten case studies for five days have been described and analyzed.

However, the year 2007 was characterized by a sparseness of aerosol events, as can be seen in the low photometer AOD in March (measurements started after the two haze events) and in the case of 7 April, where an increased AOD seems to be at least partially connected with water vapor and a low re- fractive index. Therefore, our results from Ny-Ålesund suggest, that the spring 2007 was cleaner than average from the point of view of optical remote sensing instruments.

These clean conditions during spring 2007 might be related to the fact that only $30 \%$ of all backward trajectories during the two months under consideration came from $\mathrm{Eu}-$ rope, a lower value than typical. According to our results in Table 5, for our particular data set, air masses from Eurasia correspond to conditions with a lack of both: increased backscatter and any depolarization of the air. Our case C4 "depolarization without noticeable backscatter" - probably spurious ice crystals or, hypothetically, spurious Asian desert dust remnants which came via the Canadian Arctic towards Spitsbergen, is clearly underrepresented in the European trajectories. As expected, the stronger "aerosol-like" cases are biased in favor of the Eurasian air flow regime, but as discussed in the example of 7 April, not all increased AOD with air from Europe or Russia is actually Arctic Haze. Hence, comparing backward trajectories with our observed features, simple statements as "airflow from Eurasia especially with little precipitation, produces Arctic Haze" must be rejected.

A precise description of the necessary conditions for Arctic Haze and cloud formation and its optical effect in the Arctic troposphere is beyond the scope of this paper. Such an intent would require additional long-term ground based data over at least a decade, as well as aircraft campaigns for a comparison with in situ and remote sensing instruments, which include measurements of both the gas phase and the particle content along the possible pollution pathways.

Acknowledgements. We are very thankful to the 2007 AWIPEV base personnel Mareike Peterson, Rainer Vockenroth and Cedric Couret, especially for the daily balloon soundings and data collection. The MPLNET project is funded by the NASA Earth Observing System and Atmospheric Radiation Sciences Program.

Edited by: T. Garrett

\section{References}

Ångström, A.: The parameters of atmospheric turbidity, Tellus 16, 64-75, 1964.

Ansmann, A., Riebesell, M., Wandinger, U., Weitkamp, C., Voss, E., Lahmann, W., and Michaelis, W.: Combined Raman elasticbackscatter LIDAR for vertical profiling of moisture, aerosol extinction, backscatter, and LIDAR ratio, Appl. Phys. B Photo., 55, 18-28, 1992.

Ansmann, A., Wandinger, U., Riebesell, M., Weitkamp, C., and Michaelis, W.: Independent measurement of extinction and backscatter profiles in cirrus clouds by using a combined Raman elastic-backscatter lidar, Appl. Opt. 31, 7113-7113, 1992.

Ansmann, A., Bösenberg, J., Chaikovsky, A., Comerón, A., Eckhardt, S., Eixmann, R., Freudenthaler, V., Ginoux, P., Komguem, L., Linné, H., Márquez, M. Á. L., Matthias, V., Mattis, I., Mitev, V., Müller, D., Music, S., Nickovic, S., Pelon, J., Sauvage, L., Sobolewsky, P., Srivastava, M. K., Stohl, A., Torres, O., 
Vaughan, G., Wandinger, U., and Wiegner, M.: Long-range transport of Saharan dust to northern Europe: The 11-16 October 2001 outbreak observed with EARLINET, J. Geophys. Res.Atmos., 108, 4783, doi:10.1029/2003JD003757, 2003.

Berthier, S., Chazette, P., Pelon, J., and Baum, B.: Comparison of cloud statistics from spaceborne lidar systems, Atmos. Chem. Phys., 8, 6965-6977, 2008,

http://www.atmos-chem-phys.net/8/6965/

2008/http://www.atmos-chem-phys.net/8/6965/2008/.

Beyerle, G., Gross, M. R., Haner, D. A., Kjome, N. T., McDermid, I. S., McGee, T. J., Rosen, J. M., Schäfer, H.-J., and Schrems, O.: A Lidar and Backscatter Sonde Measurement Campaign at Table Mountain during February-March 1997: Observations of Cirrus Clouds, J. Atmos. Sciences, 58, 1275-1287, 2001.

Böckmann, C.: Hybrid regularization method for the ill-posed inversion of multiwavelength lidar data in the retrieval of aerosol size distributions, Appl. Opt., 40, 1329-1342, 2001.

Buck, A.: New Equations for Computing Vapor Pressure and Enhancement Factor, J. Appl. Meteorol., 20, 1527-1532, 1981.

Chazette, P.: The monsoon aerosol extinction properties at Goa during INDOEX as measured with lidar, J. Geophys. Res.-Atmos., 108, 4187, doi:10.1029/2002JD002074, 2003.

Cho, H.-M., Yang, P., Kattawar, G., Nasiri, S., Hu, Y., Minnis, P., Trepte, C., and Winker, D.: Depolarization ratio and attenuated backscatter for nine cloud types: analyses based on collocated CALIPSO lidar and MODIS measurements, Opt. Express, 16, 3931, 1848-1866, 2008.

Curry, J., Rossow, W., Randall, D., and Schramm, J.: Overview of Arctic Cloud and Radiation Characteristics, J. Climate, 9, 17311764, 1996.

Curry, J., Hobbs, P., King, M., Randall, D., Minnis, P., Isaac, G., Pinto, J., Uttal, T., Bucholtz, A., Cripe, D., Gerber, H., Fairall, C., Garrett, T., Hudson, J., Intrieri, J., Jakob, C., Jensen, T., Lawson, P., Marcotte, D., Nguyen, L., Pilewskie, P., Rangno, A., Rogers, D., Strawbridge, K., Valero, F., Williams, A., and Wylie, D.: FIRE Arctic Clouds Experiment, B. Am. Meteor. Soc., 81, 5-30, 2000.

Draxler, R. and Hess, G.: Description of the HYSPLIT-4 Modeling System, Air Resources Laboratory, 24 pp., 1998.

Dubovik, O., Holben, B., Eck, T., Smirnov, A., Kaufman, Y., King, M., Tanré, D., and Slutsker, I.: Variability of Absorption and Optical Properties of Key Aerosol Types Observed in Worldwide Locations, J. Atmos. Sci., 59, 590-608, 2002.

Eckhardt, S., Stohl, A., Beirle, S., Spichtinger, N., James, P., Forster, C., Junker, C., Wagner, T., Platt, U., and Jennings, S. G.: The North Atlantic Oscillation controls air pollution transport to the Arctic, Atmos. Chem. Phys., 3, 1769-1778, 2003,

http://www.atmos-chem-phys.net/3/1769/

2003/http://www.atmos-chem-phys.net/3/1769/2003/.

Eloranta, E. W.: Practical Model for the Calculation of Multiply Scattered Lidar Returns, Appl. Optics, 37, 2464-2472, 1998.

Eneroth, K., Kjellström, E., and Holmén, K.: A trajectory climatology for Svalbard; investigating how atmospheric flow patterns influence observed tracer concentrations, Phys. Chem. Earth A/B/C, 28, 1191-1203, 2003.

Engvall, A., Krejci, R., Ström, J., Minikin, A., Treffeisen, R., Stohl, A., and Herber, A.: In-situ airborne observations of the microphysical properties of the Arctic tropospheric aerosol during late spring and summer, Tellus B, 60, 392-404, 2008.
Hamonou, E., Chazette, P., Balis, D., Dulac, F., Schneider, X., Galani, E., Ancellet, G., and Papayannis, A.: Characterization of the vertical structure of Saharan dust export to the Mediterranean basin, J. Geophys. Res., 104, 22257-22270, 1999.

Herber, A., Thomason, L., and Gernandt, H.: Continuous day and night aerosol optical depth observations in the Arctic between 1991 and 1999, J. Geophys. Res.-Atmos., 107, 4097, doi:10.1029/2001JD000536, 2002.

Hu, Y., Liu, Z., Winker, D., Vaughan, M., Noel, V., Bissonnette, L., Roy, G., and McGill, M.: Simple relation between lidar multiple scattering and depolarization for water clouds, Opt. Lett., 31, 1809-1811, 2006.

Hu, Y., Vaughan, M., Liu, Z., Lin, B., Yang, P., Flittner, D., Hunt, B., Kuehn, R., Huang, J., Wu, D., Rodier, S., Powell, K., Trepte, C., and Winker, D.: The depolarization - attenuated backscatter relation: CALIPSO lidar measurements vs. theory, Opt. Express, 15, 5327-5332, 2007.

Intrieri, J., Shupe, M., Uttal, T., and McCarty, B.: An annual cycle of Arctic cloud characteristics observed by radar and lidar at SHEBA, J. Geophys. Res.-Oceans, 107, 8030, doi:10.1029/2000JC000423, 2002.

Kahl, J.: Characteristics of the low-level temperature inversion along the Alaskan Arctic coast, Int. J. Climatol., 10, 537-548, 1990.

Klett, J.: Stable analytical inversion solution for processing lidar returns, Appl. Opt., 20, 211-220, 1981.

Koch, D. and Hansen, J.: Distant origins of Arctic black carbon: A Goddard Institute for Space Studies ModelE experiment, J. Geophys. Res.-Atmos., 110, 4204, doi:10.1029/2004JD005296, 2005.

Korhonen, H., Carslaw, K. S., Spracklen, D. V., Ridley, D. A., and Ström, J.: A global model study of processes controlling aerosol size distributions in the Arctic spring and summer, J. Geophys. Res., 113, D08211, doi:10.1029/2007JD009114, 2008.

Lampert, A., Ritter, C., Hoffmann, A., Gayet, J.-F., Mioche, G., Ehrlich, A., Dörnbrack, A., Wendisch, M., and Shiobara, M.: Observations of boundary layer, mixed-phase and multi-layer Arctic clouds with different lidar systems during ASTAR 2007, Atmos. Chem. Phys. Discuss., 9, 15125-15179, 2009, http://www.atmos-chem-phys-discuss.net/9/15125/ 2009/http://www.atmos-chem-phys-discuss.net/9/15125/2009/.

Law, K. S. and Stohl, A.: Arctic Air Pollution: Origins and Impacts, Science (New York, NY), 315, 1537-1540, 2007.

Lynch, D. K., Sassen, K., Del Genio, A., Heymsfield, A. J., Minnis, P., Platt, M., Quante, M., Schumann, U., and Sundqvist, H.: Cirrus: The Future, Oxford University Press, USA, 2002.

Miloshevich, L. M., Vömel, H., Whiteman, D. N., Lesht, B. M., Schmidlin, F. J., and Russo, F.: Absolute accuracy of water vapor measurements from six operational radiosonde types launched during AWEX-G and implications for AIRS validation, J. Geophys. Res., 111, D09S10, 2006.

Morrison, H., Pinto, J., Curry, J., and McFarquhar, G.: Sensitivity of modeled arctic mixed-phase stratocumulus to cloud condensation and ice nuclei over regionally varying surface conditions, J. Geophys. Res.-Atmos., 113, 5203, doi:10.1029/2007JD008729, 2008.

Orgis, T., Brand, S., Schwarz, U., Handorf, D., Dethloff, K., and Kurths, J.: Influence of interactive stratospheric chemistry on large-scale air mass exchange in a global circulation model, Eur. 
Phys. J. Special Topics, Springer, 174, 1, 257-269, 2009.

Pal, S. and Carswell, A.: Polarization properties of lidar backscattering from clouds, Appl. Opt., 12, 1530-1535, 1973.

Pfeiffer, S.: Modeling cold cloud processes with the regional climate model REMO, Ph.D. thesis, 2006.

Pinto, J.: Autumnal Mixed-Phase Cloudy Boundary Layers in the Arctic, J. Atmos. Sci., 55, 2016-2038, 1998.

Pinto, J., Curry, J., and Intrieri, J.: Cloud-aerosol interactions during autumn over Beaufort Sea, J. Geophys. Res., 106, 15077-15098, 2001.

Quinn, P., Shaw, G., Andrews, E., Dutton, E., Ruoho-Airola, T., and Gong, S.: Arctic haze: current trends and knowledge gaps, Tellus B, 59, 99-114, 2007.

Reichardt, J., Reichardt, S., Behrendt, A., and McGee, T.: Correlations among the optical properties of cirrus-cloud particles: Implications for spaceborne remote sensing, Geophys. Res. Lett., 29, 140000-140001, 2002.

Rinke, A., Dethloff, K., and Fortmann, M.: Regional climate effects of Arctic Haze, Geophys. Res. Lett., 31, L16202, doi:10.1029/2004GL020318, 2004.

Ritter, C., Kirsche, A., and Neuber, R.: Tropospheric Aerosol Characterized by a Raman LIDAR Over Spitsbergen, in: 22nd International Laser Radar Conference (ILRC 2004), edited by: Pappalardo, G. and Amodeo, A., vol. 561 of ESA Special Publication, 459 pp., 2004.

Ritter, C., Hoffmann, A., Osterloh, L., and Böckmann, C.: Estimation of the Liquid Water Content of a low level Arctic winter cloud, in: 24th International Laser Radar Conference (ILRC 2008), 1, 597-582, 2008.

Rowe, P., Miloshevich, L., Turner, D., and Walden, V.: Dry Bias in Vaisala RS90 Radiosonde Humidity Profiles over Antarctica, J. Atmos. Ocean. Tech., 25, 1529-1541 2008.

Sassen, K. and Benson, S.: A Midlatitude Cirrus Cloud Climatology from the Facility for Atmospheric Remote Sensing. Part II: Microphysical Properties Derived from Lidar Depolarization, J. Atmos. Sci., 58, 2103-2112, 2001.

Scheuer, E., Talbot, R., Dibb, J., Seid, G., DeBell, L., and Lefer, B.: Seasonal distributions of fine aerosol sulfate in the North American Arctic basin during TOPSE, J. Geophys. Res.-Atmos., 108, 18-11, 2003.

Schweiger, A., Lindsay, R., Key, J., and Francis, J.: Arctic clouds in multiyear satellite data sets, Geophys. Res. Lett., 26, 1845-1848, 1999.

Shaw, G.: The Arctic Haze Phenomenon, B. Am. Meteor. Soc., 76, 2403-2414, 1995.

Shiobara, M., Yabuki, M., and Kobayashi, H.: A polar cloud analysis based on Micro-pulse Lidar measurements at Ny-Ålesund, Svalbard and Syowa, Antarctica, Phys. Chem. Earth A/B/C, 28, 1205-1212, 2003.

Shiobara, M., Yabuki, M., Neuber, R., Spinhirne, J. D., Welton, E. J., Campbell, J. R., Hart, W. D., and Berkoff, T. A.: Arctic experiment for ICESat/GLAS ground validation with a MicroPulse Lidar at Ny-Ålesund, Svalbard, Polar Meteor. Glaciol., 20, 28-39, 2006.

Shupe, M. and Intrieri, J.: Cloud Radiative Forcing of the Arctic Surface: The Influence of Cloud Properties, Surface Albedo, and Solar Zenith Angle, J. Climate, 17, 616-628, 2004.

Shupe, M., Kollias, P., Persson, P., and McFarquhar, G.: Vertical Motions in Arctic Mixed-Phase Stratiform Clouds, J. Atmos.
Sci., 65, 1304-1322, 2008.

Solomon, S. and Qin, D.: Climate Change 2007 - The Physical Science Basis, Contribution of Working Group I to the Fourth Assessment Report of the IPCC, http://www.ipcc.ch/ipccreports/ ar4-wg1.htm, 2007.

Spinhirne, J. D.: Micro pulse lidar, Institute of Electrical and Electronics Engineers, 31, 48-55, 1993.

Stohl, A.: Characteristics of atmospheric transport into the Arctic troposphere, J. Geophys. Res.-Atmos., 111, D11306, doi:10.1029/2005JD006888, 2006.

Stohl, A., Berg, T., Burkhart, J. F., Fjǽraa, A. M., Forster, C., Herber, A., Hov, Ø., Lunder, C., McMillan, W. W., Oltmans, S., Shiobara, M., Simpson, D., Solberg, S., Stebel, K., Ström, J., Tørseth, K., Treffeisen, R., Virkkunen, K., and Yttri, K. E.: Arctic smoke - record high air pollution levels in the European Arctic due to agricultural fires in Eastern Europe in spring 2006, Atmos. Chem. Phys., 7, 511-534, 2007,

http://www.atmos-chem-phys.net/7/511/

2007/http://www.atmos-chem-phys.net/7/511/2007/.

Stone, R., Dutton, E., Harris, J., and Longenecker, D.: Earlier spring snowmelt in northern Alaska as an indicator of climate change, J. Geophys. Res.-Atmos., 107, 4089, doi:10.1029/2000JD000286, 2002.

Treffeisen, R., Rinke, A., Fortmann, M., Dethloff, K., Herber, A., and Yamanouchi, T.: A case study of the radiative effects of Arctic aerosols in March 2000, Atmos. Environ., 39(5), 899-911, 2005.

Treffeisen, R., Krejci, R., Ström, J., Engvall, A. C., Herber, A., and Thomason, L. W.: Humidity observations in the Arctic troposphere over Ny-Ålesund, Svalbard based on 14 years of radiosonde data, Atmos. Chem. Phys. Discuss., 7, 1261-1293, 2007,

http://www.atmos-chem-phys-discuss.net/7/1261/

2007/http://www.atmos-chem-phys-discuss.net/7/1261/2007/.

van de Hulst, H. C.: Light scattering by small particles, Wiley VCH, 1981.

Vavrus, S. and Waliser, D.: An Improved Parameterization for Simulating Arctic Cloud Amount in the CCSM3 Climate Model, J. Climate, 21, 5673-5687, 2008.

Verlinde, J., Harrington, J., McFarquhar, G., Yannuzzi, V., Avramov, A., Greenberg, S., Johnson, N., Zhang, G., Poellot, M., Mather, J., Turner, D., Eloranta, E., Zak, B., Prenni, A., Daniel, J., Kok, G., Tobin, D., Holz, R., Sassen, K., Spangenberg, D., Minnis, P., Tooman, T., Ivey, M., Richardson, S., Bahrmann, C., Shupe, M., Demott, P., Heymsfield, A., and Schofield, R.: The Mixed-Phase Arctic Cloud Experiment, B. Am. Meteor. Soc., 88, 205-221, 2007.

Vömel, H. H., Selkirk, L., Miloshevich, J., Valverde-Canossa, J., Valdes, J., and Diaz, J.: Radiation Dry Bias of the Vaisala RS92 Humidity Sensor, J. Atmos. Ocean. Tech., 24, 953-963, 2007.

Währn, J., Oyj, V., Rekikoski, I., Jauhiainen, H., and Hirvensalo, J.: New Vaisala Radiosonde RS92: Testing and Results from the Field, Eighth Symposium on Integrated Observing and Assimilation Systems for Atmosphere, Oceans, and Land Surface, 2004.

Welton, E. and Campbell, J.: Micropulse Lidar Signals: Uncertainty Analysis, J. Atmos. Ocean. Tech., 19, 2089-2094, 2002.

WMO: Guide to Meteorological Instruments and Methods of Observation 2008, online available at: http: //www.wmo.int/pages/prog/www/IMOP/publications/ 
CIMO-Guid $\backslash \%$ e/CIMO_Guide-7th_Edition-2008.html, 2008.

Wyser, K., Jones, C., Du, P., Girard, E., Willen, U., Cassano, J., Christensen, J., Curry, J., Dethloff, K., Haugen, J., Jacob, D., Koltzow, M., Laprise, R., Lynch, A., Pfeifer, S., Rinke, A., Serreze, M., Shaw, M., Tjernstrom, M., and Zagar, M.: An evaluation of Arctic cloud and radiation processes during the SHEBA year: simulation results from eight Arctic regional climate models, Clim. Dynam., 30, 203-223, 2008.
Yamanouchi, T., Treffeisen, R., Herber, A., Shiobara, M., Yamagata, S., Hara, K., Sato, K., Yabuki, M., Tomikawa, Y., Rinke, A., Neuber, R., Schumacher, R., Kriews, M., Ström, J., Schrems, O., and Gernandt, H.: Arctic Study of Tropospheric Aerosol and Radiation (ASTAR) 2000: Arctic haze case study, Tellus B, 57, 141-152, 2005. 